\title{
LAS SOCIEDADES FORMATIVAS DE SAN PEDRO DE ATACAMA: AsENTAMIENTO, CRONOLOGÍA Y PROCESO
}

\author{
Carolina Agüero y Mauricio Uribe ${ }^{2}$
}

\section{* Introducción}

\section{Resumen}

Se analizan críticamente las aproximaciones que tradicionalmente han explicado el origen y desarrollo de las sociedades formativas en los oasis de San Pedro de Atacama, al mismo tiempo que se evalúa el proceso formativo local a partir del eje que abarcan estos oasis junto a Calar y Puripica, siguiendo el curso del río Vilama. Se propone una explicación para comprender las sociedades formativas de la Puna Salada y su consecuente articulación al tráfico interno y externo de bienes que habría caracterizado a su complejidad social posterior. Para esto, establecemos un orden secuencial de las ocupaciones formativas, sus fechados absolutos y determinamos su naturaleza e incorporación a las prácticas caravaneras propias de los oasis de San Pedro.

Palabras claves: San Pedro de Atacama - Período Formativo - arqueología de asentamiento - Chile - Andes del Sur. approaches for explaining the origins and development of Formative Period societies in the San Pedro de Atacama oasis. We evaluate the local formative process in the axes of the oases with Calar and Puripica, following the course of the Vilama River. We then propose an explanation that allows us to understand the Formative societies of the Puna Salada as well as their articulation to the intra- and inter- regional traffic of goods, which characterized the development of these societies' social complexity in the following periods. To build this model we establish a sequence for the Formative Period occupations, their absolute dates, and determine their nature as well as their incorporation into the caravan practices typical of San Pedro de Atacama.

Key words: San Pedro de Atacama - Formative Period - settlement archaeology - Chile - South Central Andes. Recibido: enero 2011. Aceptado: diciembre 2011.
No es un hecho desconocido que la ausencia de datos en San Pedro de Atacama ha dificultado una mejor discusión sobre la historia cultural de estos oasis en el Formativo. Prueba de ello es que el modelo que ha sido mayormente utilizado se ha formulado de acuerdo a las evidencias obtenidas en el "transecto Tulan", en el extremo opuesto de la Cuenca de Atacama (Núñez 1995).

Una serie de investigaciones llevadas a cabo de manera sostenida en quebrada Tulan, principalmente en sitios domésticos y ceremoniales, ha demostrado que allí se desarrolló un modo de vida pastoralista cuyo origen quebradeño ha sido consistentemente señalado (Núñez 1995, 2005). Los ancestrales conocimientos del entorno habrían propiciado que, desde campamentos semipermanentes establecidos en dicha quebrada, se articulara un extenso territorio distribuido en distintos pisos altitudinales. Tales prácticas habrían promovido la domesticación de los camélidos, haciendo posible situaciones formativas agropastoralistas; es decir, con crianza de llamas y complementariamente, horticultura, caza y recolección. Solo entonces se habrían construido aldeas en la quebrada, las que hacia el $400 \mathrm{AC}$ son abandonadas para ocupar los oasis, donde, con el apoyo de la recolección de frutos de algarrobo y chañar, se crearon complejos aldeanos en estrecha relación con el control del espacio agrícola (Núñez 1995). Sin embargo, no queda claro por qué una sociedad que había logrado un manejo eficiente

\footnotetext{
1 Instituto de Investigaciones Arqueológicas y Museo, Universidad Católica del Norte. Gustavo Le Paige 380, San Pedro de Atacama, CP 1410000, CHILE. Email: maguero@ucn.cl

2 Departamento de Antropología, Facultad de Ciencias Sociales, Universidad de Chile. Ignacio Carrera Pinto 1045, Nuñoa, Santiago, CHILE. Email: mur@uchile.cl
} 


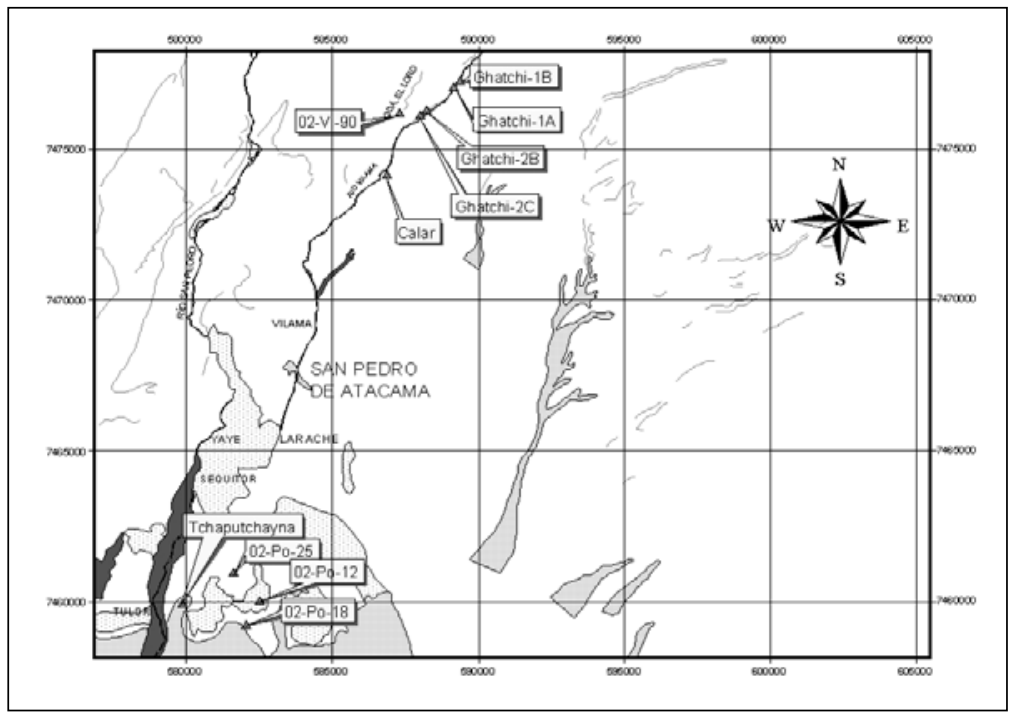

Figura 1. Sitios sondeados en los oasis de San Pedro y quebrada de Vilama.

de camélidos, llevándola a liderar la complejidad social emergente en Atacama (Núñez 1995, 2005; Núñez et al. 2006) optó por abandonar sus asentamientos y dedicarse a la agricultura de manera complementaria. Fue la ausencia de investigaciones en San Pedro de Atacama mismo, que no proporcionaron datos previos al Formativo Tardío, lo que llevó a que la aplicación de este modelo nunca fuera cuestionada. No obstante, su superposición en los oasis siempre fue realizada en términos hipotéticos (Berenguer et al. 1986; Tarragó 1989; Núñez 1992, 1995, 2005; Llagostera 1996; Llagostera y Costa 1999). Todo ello hacía cada vez más ineludible la necesidad de ponerlo a prueba.

Es así como, al iniciar esta investigación, vimos que los contextos domésticos estudiados en San Pedro eran solo cuatro: Tulor 1, Tulor 4, Coyo Aldea y Calar (Le Paige 1957-58, 1964; Serracino 1976; Llagostera et al. 1984; Barón 1986; Llagostera 1988; Orellana 1988-1989, 1990; Stovel 1997). Varios de estos sitios no fueron fechados, o bien, las dataciones no fueron calibradas, de manera que sus fechas y secuencias estratigráficas se extrapolaron desde otras zonas, lo que sin duda no facilitaba una discusión del proceso de ocupación de los oasis. Por otra parte, la sistematización de la cultura material es relativamente reciente, sobre todo en lo que se refiere a la alfarería, la lítica y la arquitectura, así como también el arte rupestre (Carrasco 2006 Ms; Montt $2006 \mathrm{a}$ y b; Uribe 2006; Adán y Urbina 2007). En suma, el cuerpo de datos provenientes de los oasis y quebradas aledañas no proporcionaban la base para una mejor comprensión del tránsito hacia una sociedad formativa y su consecuente participación en el tráfico de bienes interno y externo que caracterizó el desarrollo y esplendor de su complejidad social posterior (Núñez y Dillehay 1995 [1979]; Llagostera 1996).

Teniendo en mente lo anterior, pensamos que este proceso es posible de evaluar en el eje que une San Pedro de Atacama, Calar y Puripica, siguiendo el curso del río Vilama. Precisamente, es en Puripica donde Núñez y colaboradores (1999: 130) observaron manifestaciones hortícolas "muy antiguas originadas en prácticas arcaicas".

De esta manera, el año 2004 realizamos una prospección de los oasis y de la quebrada de Vilama, como primera aproximación sistemática al asentamiento temprano en los oasis de Atacama, cuyos resultados hicieron aún más necesario reevaluar los patrones de asentamiento propuestos para los oasis (Agüero 2005). A partir de aquel trabajo, seleccionamos 10 sitios habitacionales de la quebrada (Ghatchi 2C, Ghatchi 2B, Ghatchi 1B, Ghatchi 1A, Ghatchi o2Vigo y Calar), y de los oasis (02 Po18, O2 Po25 y 02 Polz en Poconche, y Tchaputchayna, en Beter) (Fi- 


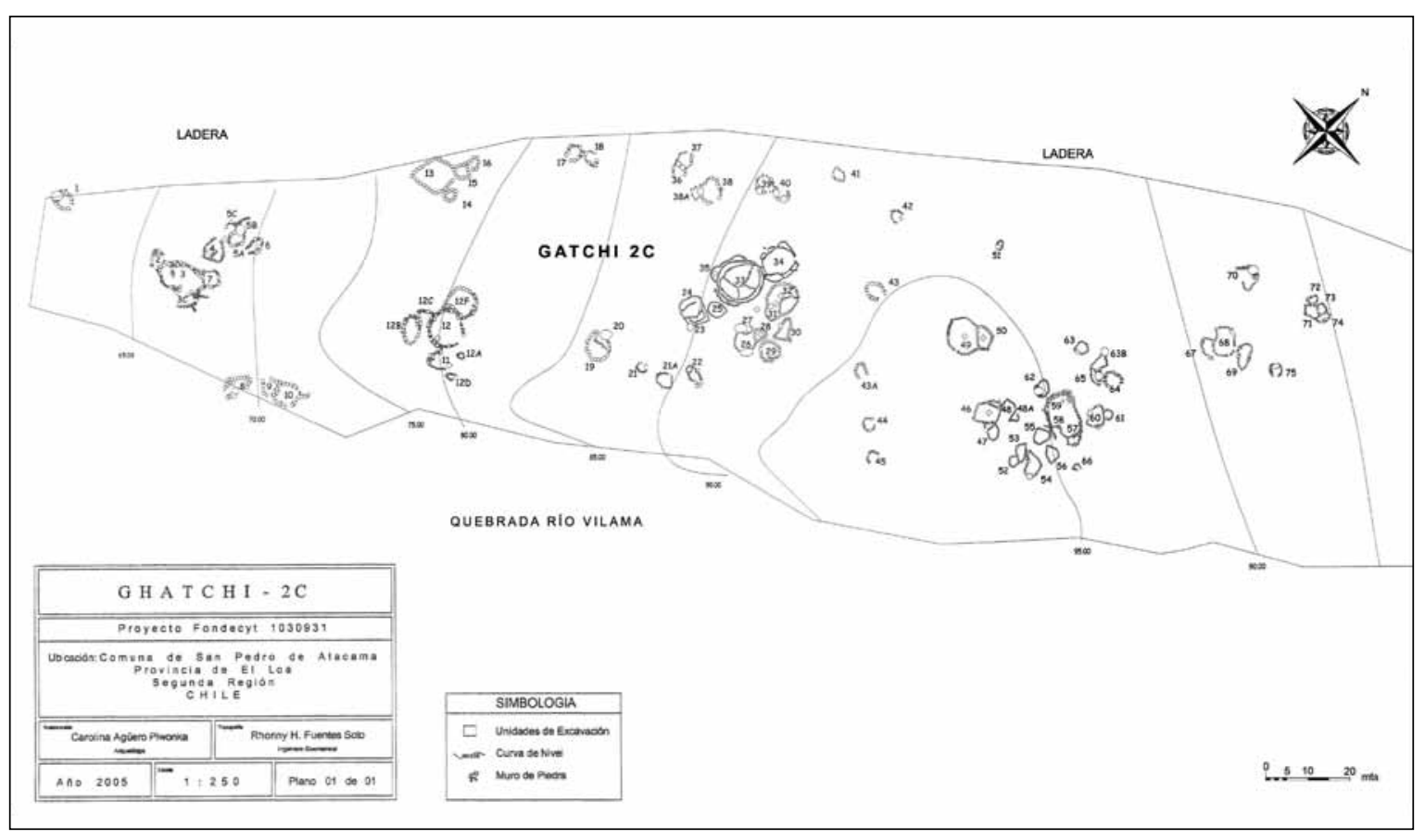

Figura 2. Plano de Ghatchi $2 \mathrm{C}$.

gura 1), para que a través de excavaciones, arqueometría y análisis funcionales de estos asentamientos, fuera posible ofrecer un orden secuencial de las ocupaciones formativas, determinando su naturaleza e incorporación a las prácticas caravaneras que se han señalado como propias de San Pedro de Atacama.

\section{* Nuevos datos: Asentamientos, contextos Y CRONOLOGÍA}

\section{Quebrada de Vilama}

1. Ghatchi $2 \mathrm{C}$ (02Vi91). Es uno de los sitios emplazados en la meseta de Ghatchi 2 (Le Paige 1963, 1964), aledaña al río Vilama. El conjunto arquitectónico se compone de 81 estructuras dispersas, algunas depresionadas, distribuidas en una superficie de $10.850 \mathrm{~m}^{2}$, lo que da

3 Como parte de este proyecto exploratorio, realizamos intervenciones de un metro por un metro abarcando el 10\% de los espacios construidos, túmulos, o superficie con evidencias culturales de los sitios. una densidad de 75 recintos por hectárea, indicando una ocupación poco densa y escasamente aglutinada (Adán y Urbina 2007).

Este conjunto se organiza en 14 pequeños conglomerados de dos a cuatro recintos, y 35 estructuras aisladas (Figura 2), señalando ocupaciones de larga data, arcaicas, formativas y transicionales, como señalaba Le Paige $(1963,1964)$.

Los recintos tienen principalmente plantas circulares, ovales y subcirculares, seguidas por las formas irregulares, siendo las plantas ortogonales prácticamente inexistentes. Los de planta circular abarcan entre $1 \mathrm{~m}^{2}$ y más de $100 \mathrm{~m}^{2}$, indicando cierto conocimiento para edificar espacios, con una clara herencia arcaica, donde las probables variaciones funcionales no se relacionan con la forma de las plantas. Los muros se construyeron con piedras, incorporándose también turba recortada para conformar bloques. Se observan paramentos de hilada simple con una significativa ocurrencia de muros dobles y dobles con relleno, los que se emplean con mayor frecuencia en el conjunto central con el patrón de recinto mayor y otros 


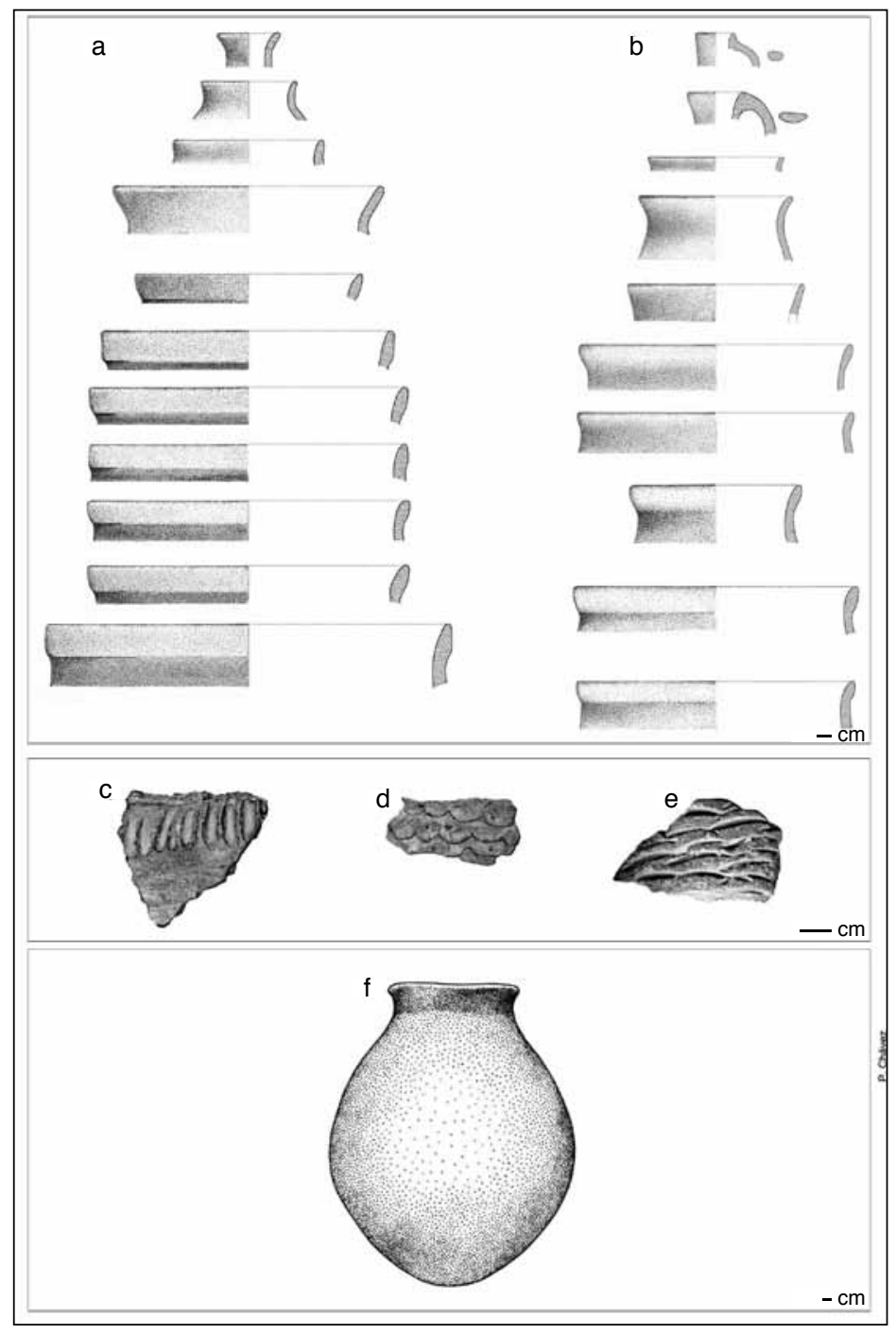

Figura 3. Cerámica del Período Formativo Temprano: a) Formas del tipo Los Morros A (restringidas de labio convexo y de labio reforzado); b) Formas del tipo Los Morros B (restringidas de labio convexo y de labio reforzado); c, d y e) Fragmentos modelados del tipo Los Morros (inciso, corrugado y con impresiones de uñas, respectivamente); f) Loa Café Alisado (cántaro).

menores asociados en distribución radial o "pétalos" (sensu Núñez 1994). Un elemento constructivo interesante es la disposición de piedras alargadas en sentido perpendicular a la superficie, constituyendo verdaderos pilares para soportar los paramentos. Ellas cumplen, además, fines fundacionales, enterrándose en algunos casos bajo un primer nivel ocupacional. Otro elemento es el empleo de grandes bloques rocosos a los cuales se adosan los paramentos para formar las estructuras. Por último, destaca el uso de morteros cónicos agotados en los muros, lo cual señala continuas labores de curaduría y una indicación del modo de vida que se abandona y del que se inaugura.

Esta variabilidad muestra dos patrones constructivos y momentos ocupacionales. Uno más temprano con estructuras irregulares y de planta circular; y otro más tardío, probablemente transicional y formativo que desarrolla el patrón "recinto mayor y menores asociados en distribución radial" con una construcción más ela- 


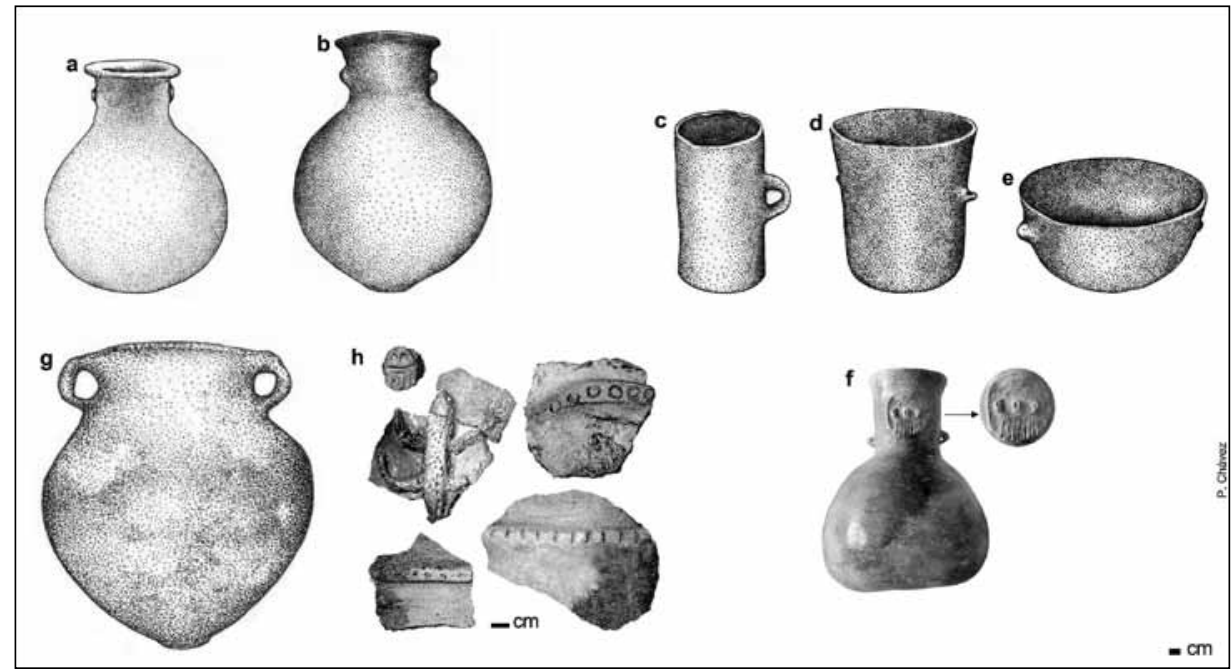

Figura 4. Cerámica del Período Formativo Tardío: a y b) San Pedro Rojo Pulido-Toconao (botellones y cántaros); c, d, e y f) San Pedro Negro Pulido-Sequitor (vasos, escudilla y botella); gy h) Loa Rojo Alisado (cántaro y fragmentos).

borada e implicando un mayor costo energético, formal y conceptualmente vinculada al manejo de ganado por parte de comunidades pastoriles. Estas estructuras conforman, en la parte central del asentamiento, un sector más aglutinado configurándose una tendencia al nucleamiento edilicio que caracterizaría el patrón de evolución arquitectónica en el Formativo. Conceptualmente, creemos que este patrón expresa el modo de vida pastoril, ya que su forma representa un corral con sus "chiqueros" o "enfermerías". ${ }^{4}$ Ello no implica que necesariamente ese fuera su uso, ya que la manufactura y la inversión de recursos excede los requerimientos necesarios para ello (Adán y Urbina 2007). Pero, simbólicamente constituyen un primer indicio de arquitectura pública de uso ceremonial, avalado por algunos entierros fundacionales de niños en sitios como Ghatchi 1A y Calar, además de Tulan 54 (Núñez 1994: 89). Paralelamente, el registro de surcos intencionales en algunas piedras que conforman los recintos de Ghatchi $2 \mathrm{C}$, remite a manifestaciones rupestres propias de sitios arcaicos y formativos de la fase Tilocalar, con ocupaciones sedentarias de base pecuaria dominante, y actividades de caza y recolección e indicios de prácticas iniciales y establecidas de pastoreo (Núñez 1981: 158 ; 1994).

\footnotetext{
4 Se denomina así a los recintos en los que se deja a los animales pequeños cuando requieren cuidados.
}

Los depósitos de las 13 unidades excavadas alcanzaron profundidades entre 20 y $55 \mathrm{~cm}$, proporcionando gran cantidad de material lítico y óseo, aunque escasa cerámica, representada por solo seis fragmentos correspondientes a tipos tempranos (Los Morros, Loa Café Alisado y Loa Rojo Alisado) (Figuras 3 y 4). En cuanto al material lítico, en superficie se contabilizaron 211 morteros de hueco cónico, cinco con dos superficies de uso (hueco cónico y plana), cuatro tacitas, cuatro metates y tres conas (o conanas) además de 20 manos de moler, sin contar los artefactos de este tipo insertos en los muros. También destacan las preformas, las puntas de proyectil, los cuchillos e instrumentos de uso cortante, las cuentas, los perforadores, los raspadores y los núcleos. Las puntas de proyectil son principalmente lanceoladas $y$ de bases convexas, sobre láminas de basaltos-andesitas, silíceas y obsidianas. Los perforadores se asocian directamente a las cuentas discoidales de concha y mineral de cobre. Los 19.403 desechos de talla señalan actividades de desbaste de núcleos para la obtención de matrices (láminas). Los instrumentos incluyen acciones de corte, perforado y raspado, entre otras, indicando que, además del aprovisionamiento de materias primas, desbaste de núcleos y obtención de matrices, en el sitio se realizan actividades domésticas como faenamiento y procesamiento, a juzgar por la presencia de leznas, raspadores y cuchillos, lo que con seguridad se vincula a diferencias 


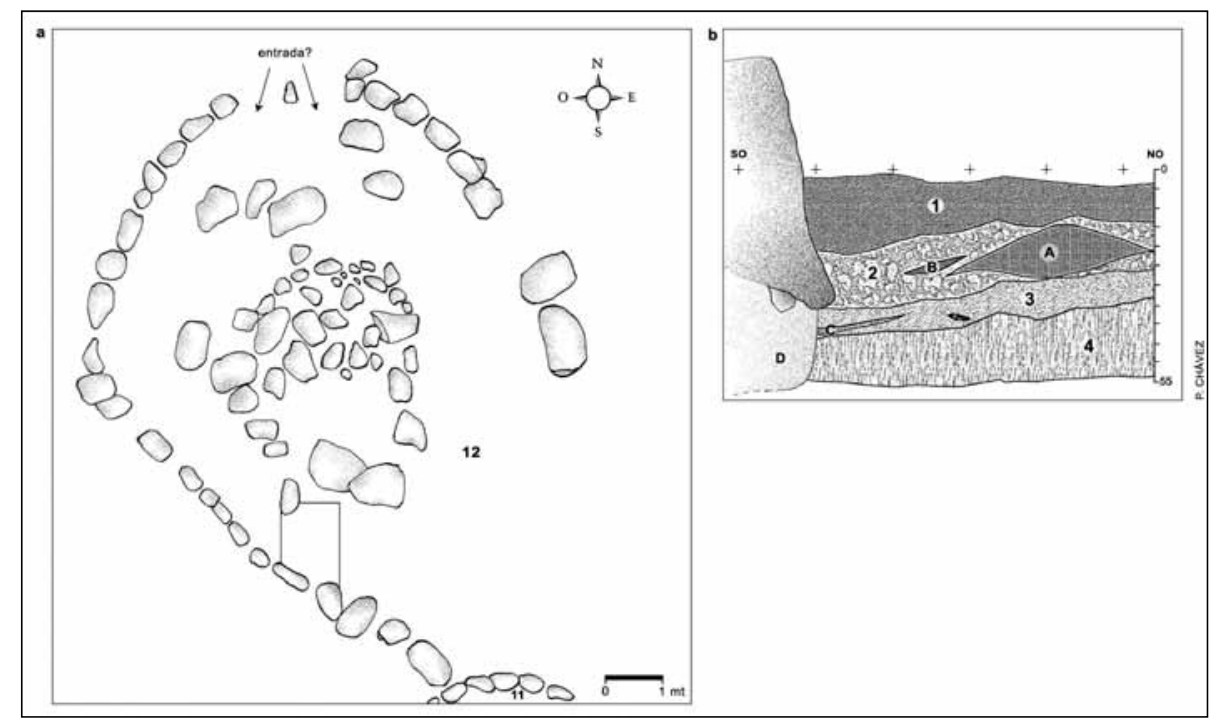

Figura 5. a) Ghatchi 2C: Recinto 12, unidad 1; b) Perfil oeste (fechado se obtuvo de la capa 3; D corresponde a un foso que cortó la ocupación para asentar la piedra del muro).

temporales de ocupación (Carrasco 2006 Ms). Los restos óseos corresponden a camélidos, roedores (chinchillidos, Ctenomys fulvus y sigmodontinos), aves, cánidos, peces y moluscos, y se concentran en los recintos 4,11 y 12 (González 2006 Ms).

Fuera del conjunto central, el recinto 12 (Figura 5a) presenta la principal intensidad de ocupación, conteniendo la mayoría de los huesos y restos líticos en un depósito de $55 \mathrm{~cm}$ con dos eventos (Figura 5b). El primero de ellos, en la capa 3 y bajo el muro, se fechó en $4885 \pm 125$ (40003350 cal. AC), contemporáneo a Puripica I (Núñez et al. 1999), que se emplaza solo unos pocos kilómetros aguas arriba. Se relaciona a un fogón y a puntas de proyectil lanceoladas y doble punta, astillas de camélido y en menor grado de chinchillido y Ctenomys $f$. con huellas de combustión, restos de ave, valvas de molusco calcinadas (p.e., Choro mytilus), pez y cánido, además de cinco artefactos de hueso de camélido con huellas de combustión. La ocupación más reciente, en la capa 2 , se asocia a un fogón, puntas lanceoladas y a la construcción del muro, para lo cual se habría cavado rompiendo el fogón de la ocupación previa. La mayoría de los huesos son de camélido (esqueleto axial y patas bajas, señalando que el faenamiento se produjo en el sitio), todos con huellas de combustión. También hay restos de Ctenomys $f$. y chin- chillido con huellas de combustión, fragmentos de Choro mytilus calcinadas, pez, ave y cánido, además de dos artefactos de hueso con huellas de combustión. De acuerdo a los tipos de instrumentos líticos, ambas ocupaciones corresponderían a un único componente cultural (Carrasco $2006 \mathrm{Ms}$ ). Este recinto corresponde a un conjunto situado en un pequeño montículo producto de la acumulación de basuras en donde se concentra una gran cantidad de morteros desechados, lo que junto a los dos densos fogones descritos, sugiere un sector de actividades domésticas reutilizado durante varias generaciones. Lo anterior, además de la inversión de energía que significa la construcción de recintos semihundidos y muros con fundamentos, indica una ocupación más intensa y/o recurrente con un mayor grado de estabilidad por parte de cazadores recolectores tardíos.

Por su parte, el conjunto central corresponde a ocupaciones más tardías a juzgar por la escasa evidencia lítica recuperada, en donde el uso de las materias primas se restringe principalmente a lo expeditivo. No obstante, el recinto 33 exterior mostró un basural estratificado y complejo con evidencias de consumo de ave, camélido y un claro predominio de roedores. Los depósitos alcanzan entre 10 y $25 \mathrm{~cm}$ y son asignables al Formativo. El predominio de fragmentos de vasijas restringidas, espe- 


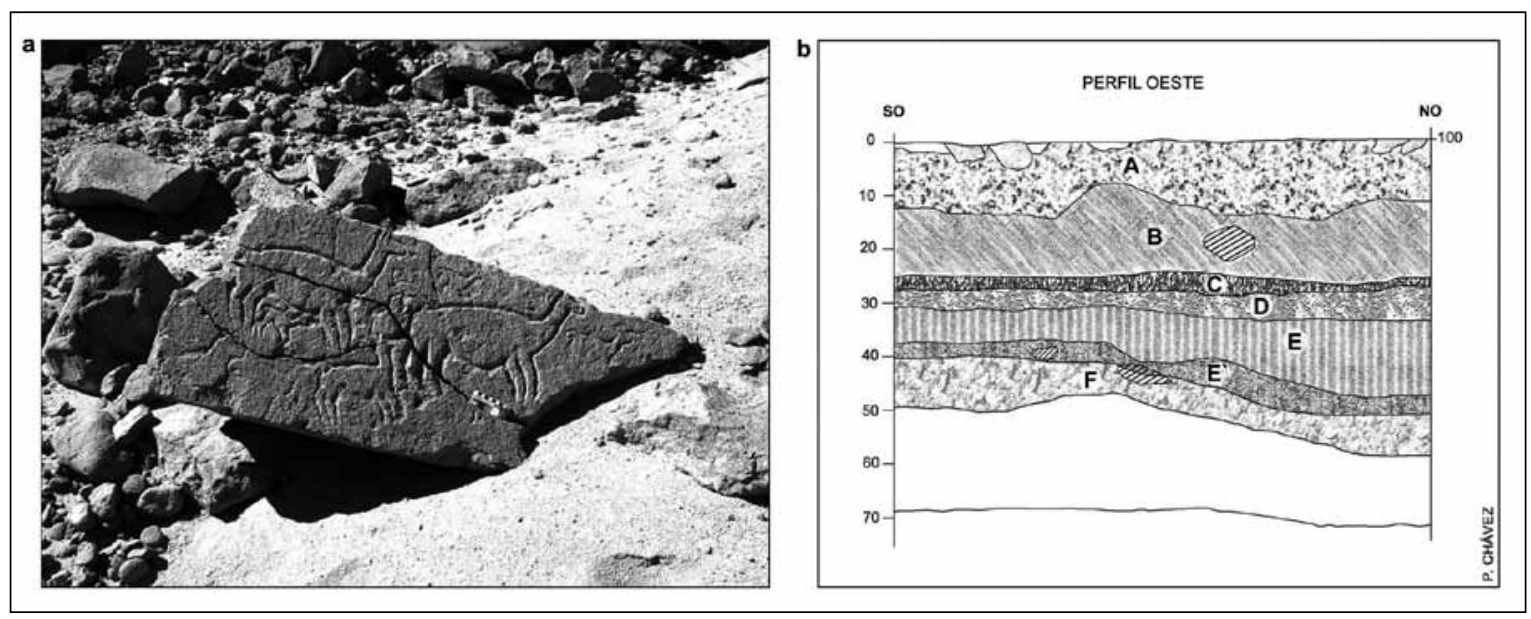

Figura 6. a) Ghatchi O2-Vi-9o: Panel 24; b) Unidad 1, perfil oeste.

cialmente jarros (tipo Los Morros), indican escasa actividad doméstica con consumo de líquidos, apoyando la utilización ceremonial esporádica del conjunto. En estos recintos, se comenzaría a desarrollar el patrón "recinto mayor y menores asociados en distribución radial", elaborado con mayor costo energético y, conceptualmente, vinculado al manejo de ganado por parte de comunidades formativas iniciales (Adán y Urbina 2007).

En suma, este es uno de los sitios complejos de Vilama, debido a la enorme diferencia que existe entre los tipos de recintos así como de sus depósitos, que revelaron al menos dos momentos de ocupación en una gradiente que va desde el sur de la meseta de Ghatchi 2 hacia el norte de ésta. El primero, correspondiente a un sector de cazadores recolectores tardíos; el segundo, probablemente perteneciente al Formativo Temprano, donde se encuentra el conjunto estructural central. Salvo el primer conglomerado arcaico, el resto fue utilizado durante momentos muy acotados o pasajeros, sugiriendo una presencia poco permanente y/o alta movilidad. La clasificación arquitectónica de Ghatchi indica una larga historia ocupacional que se desarrolla en medio de las transformaciones socioeconómicas cruciales para los grupos cazadores recolectores de Atacama. Al igual que ciertos sectores de Calar, el patrón arquitectónico es sumamente estandarizado, denotando un claro parentesco tecnológico y simbólico con otros asentamientos tempranos de quebradas circumpuneñas y valles orientales andinos.
Asimismo, llama la atención el surgimiento de espacios comunitarios de carácter congregacional característicos de inicios del Formativo (Adán y Urbina 2007; Adán et al. 2007). Los aspectos constructivos son elocuentes en este sentido, implicando una fuerte selectividad en la disposición de los materiales, sobre todo en los recintos más cuidados, como aquellos circulares de gran tamaño en el centro del sitio. Todo esto vincula a Ghatchi $2 \mathrm{C}$ con la tradición arquitectónica más antigua y que mejor se conoce en las quebradas aledañas al Salar de Atacama y comienza a mostrarnos un nuevo panorama más amplio de ocupación espacial, donde el río Vilama se incorpora tempranamente al medio regional.

2. Ghatchi 02Vigo. Este sitio se emplaza unos $800 \mathrm{~m}$ al suroeste de Ghatchi $2 \mathrm{C}$, y entre ambos se cuentan cerca de 50 estructuras arcaicas y formativas (Agüero 2005). El sitio ocupa un área cercana a los $20 \mathrm{~m}^{2}$ de un sector plano y otro ligeramente ataludado, a $5 \mathrm{~m}$ sobre el lecho de la quebrada y apegado a la pared de la misma. Hay bastante material cultural en superficie y un depósito estratigráfico expuesto. Sobre éste existen dos paneles rupestres de un total de 24; 23 de los cuales están en la pared de la quebrada y bloques del sector oeste, y solo uno en un bloque al este de la quebrada. El sitio presenta rasgos únicos en la factura rupestre, tales como figuras pictograbadas en el panel 24 (Figura 6a). No obstante es predominante el grabado, como en el resto de la región. Seis paneles se insertan en los estilos Calina-Puripica / 


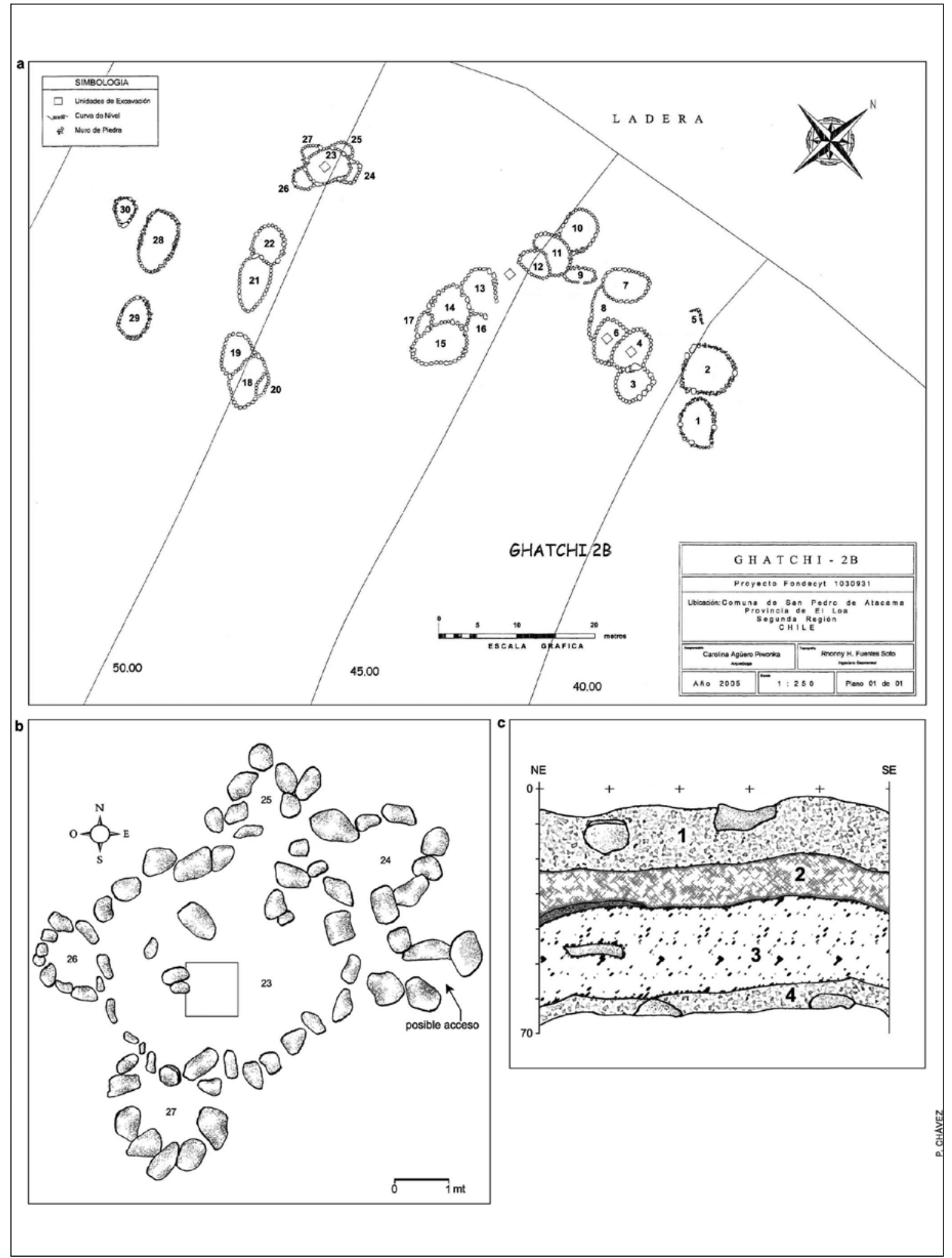

Figura 7. a) Plano de Ghatchi 2B; b) Recinto 23, unidad 1; c) Perfil este. 
Taira-Tulan y otros seis lo hacen en el estilo Taira-Tulan. Doce fueron indeterminables (Montt 2006a y b), por lo que los primeros habrían sido realizados durante la transición arcaico-formativa (ca. 3000-1200 AC), y los segundos durante el Formativo Temprano a Medio (ca. 1200 AC-100 DC). Es destacable la presencia de camélidos rupestres en contexto doméstico, siendo los únicos hallados en la cuenca del Salar junto a los de Puripica 1 y Tulan 54 (Núñez 1994: 91).

El sitio fue sondeado a los pies de los paneles 12 y 13 , alcanzando el depósito arqueológico $59 \mathrm{~cm}$ de profundidad (Figura 6b). En la capa D se distinguió un sello producto del derrumbe de la pared, que separa dos ocupaciones. La más antigua se fechó en 3685 550 AP (2204-1930 cal. $\mathrm{AC}$ ), con más restos óseos, algunos de camélidos con pintura roja, fauna circundante como aves y roedores (vizcacha y chinchilla), restos de Tessaria absinthiodes con pigmento rojo, lascas óseas y una mano de granito con restos de este pigmento, preformas lanceoladas y triangulares de obsidiana, cuchillo y perforador de sílice, núcleos de obsidiana, preformas de cuentas cilíndricas de mineral de cobre, lascas y microlascas. Es probable que el único panel pictograbado se asocie a esta primera ocupación. La ocupación más reciente se sitúa en la capa $B$ sobre el sello y fue fechada en 3190 \pm 55 AP (1531-1392 cal. $\mathrm{AC})$; presenta restos de camélido, roedor y ave, junto a lascas y microlascas de cuarzo, basalto y obsidiana. Por consiguiente, es posible que este sitio sea un campamento de tareas especializado en la manufactura de puntas lanceoladas para la caza de camélidos, probablemente arreados desde el río Vilama y encerrados en esta pequeña quebrada, donde se elaboraron los grabados y pictografías en un lapso de 600 años, desde el Arcaico Tardío hasta su transición al Formativo Temprano.

3. Ghatchi $2 B$ (o2Vi86). Conjunto de 30 estructuras emplazadas en la parte central de la meseta de Ghatchi 2 (Figura 7a). Presenta estructuras de muros simples y dobles con relleno, algunas con patrón de recinto central y otros menores adosados. La gran cantidad de morteros de hueco cónico agotados como parte de los muros sugiere una ocupación formativa sobre otra arcaica, al igual que en el conjunto central de Ghatchi $2 \mathrm{C}$. Al respecto, los depósitos de las cuatro unidades excavadas en este sitio alcanzaron profundidades entre 50 y $60 \mathrm{~cm}$, distinguiéndose un primer momento bastante efímero en algunos recintos, previo a la construcción de las estructuras y con actividades de molienda asociadas a fogones. Un segundo momento fue datado en la capa 3 del recinto 23 (Figuras $7 \mathrm{~b}$ y $7 \mathrm{c}$ ) en $2245 \pm 35 \mathrm{AP}(400-200$ cal. AC), cuando se habrían edificado los recintos semihundidos para realizar labores domésticas a juzgar por los sedimentos, restos óseos y alfarería, registrándose tipos cerámicos tempranos, especialmente Los Morros, y cierta concentración de cuentas de mineral de cobre y concha. Sin embargo, la presencia humana habría sido breve, poco intensa y habría privilegiado actividades de cocina y almacenamiento de alimentos junto al consumo de animales del ambiente circundante obtenidos por caza menor (roedores), ya que son pocos los restos de camélido. La ocupación pasajera sugerida por los depósitos y su cerámica, junto al registro lítico bastante menor, señala al sitio como un campamento destinado al aprovisionamiento de materias primas (andesita, basalto, obsidianas, sílices, toba, etc.), desbaste de núcleos y obtención de matrices, coherente con la cercanía de Loma Negra. Las preformas de punta, todas lanceoladas, están elaboradas en obsidiana negra traslúcida y algunas en silíceas blancas, lo que implica elección de rocas locales para su elaboración. También aparecen perforadores, leznas, cuchillos, manos de moler, un fragmento de pala, percutores, raspadores y bifaces. En cualquier caso, la amplia variabilidad artefactual sugiere el desarrollo de diversas actividades no especializadas, aunque la relativa escasez de desechos $(n=859)$ indica la probabilidad que el sitio se haya ocupado como un locus esporádico en la cadena operativa (Carrasco $2006 \mathrm{Ms}$ ).

4. Ghatchi IA (o2Vi75). Es un conjunto de 21 estructuras aglutinadas emplazadas en la parte central de la meseta de Ghatchi 1, cerca del río. Los recintos están construidos con muros de piedra dobles con relleno, muy destruidos por la reutilización del sitio como corral desde el Intermedio Tardío a la actualidad, de una manera similar pero más drástica que Calar (Figura 8a). Los depósitos de tres recintos excavados alcanzaron profundidades de entre 40 y $70 \mathrm{~cm}$, distinguiéndose que el sitio fue ocupado en tres momentos diferentes. En el primero, asignable al Formativo Medio, se habrían edificado los recintos semihundidos con evidencias de hoyos de postes y pozos para alimentos como maíz y algarrobo (recinto 4), realizándose rituales fundacionales con ofrendas humanas bajo los muros (recinto 12). En algunos recintos, este momento 


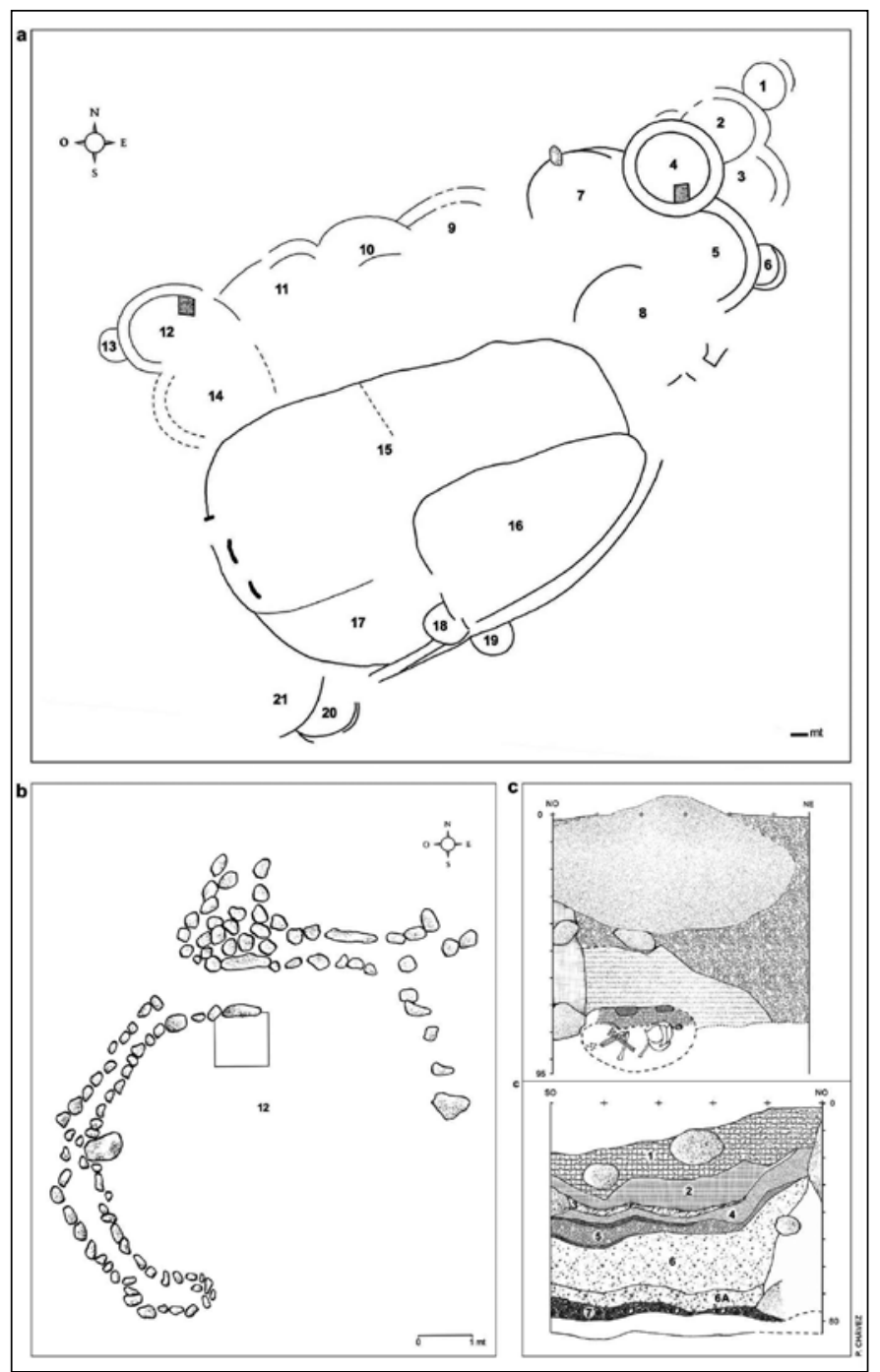

Figura 8. a) Croquis de Ghatchi 1A; b) Recinto 12, unidad 1; c) Entierro fundacional de neonato; d) Perfil oeste.

tendría una continuidad hacia el Formativo Tardío, mientras otros (recinto 4) se reocuparían, realizándose otro tipo de actos fundacionales como la ofrenda del cráneo de un niño de cinco años (Costa $2004 \mathrm{Ms}$ ). Posteriormente, los recintos se habrían reutilizado como corrales, al igual que en Calar.

En el recinto 12 (Figura $8 b$ ) fue posible definir al menos dos de las ocupaciones (Figura 8c). En la primera (capas 6 y 7), se realizó el entierro de un neonato bajo el muro y se construyó el recinto semihundido. Para esto, cavaron $40 \mathrm{~cm}$ desde la superficie original y realizaron el ritual fundacional en uno de sus bordes, distinguiéndose una pequeña fosa circular de $19 \mathrm{~cm}$ de profundidad que fue recubierta de pequeñas piedras y en la cual fue enterrado un niño de seis meses (Costa $2004 \mathrm{Ms}$ ). Estaba recostado sobre la espalda con las piernas flectadas, mirando al oeste y ofrendado tanto alrededor como arriba y abajo con restos de obsidiana y malaquita (Figuras $8 \mathrm{c}$ ). Posteriormente, esta depresión fue cubriéndose con sedimento y basuras. De aquí se obtuvo una fecha de $1895 \pm 78$ AP (113 AC-239 cal. DC), correspondiente al Formativo Medio, con cerámica temprana del Loa y Los Morros. La presencia humana habría sido poco intensa y corta con 


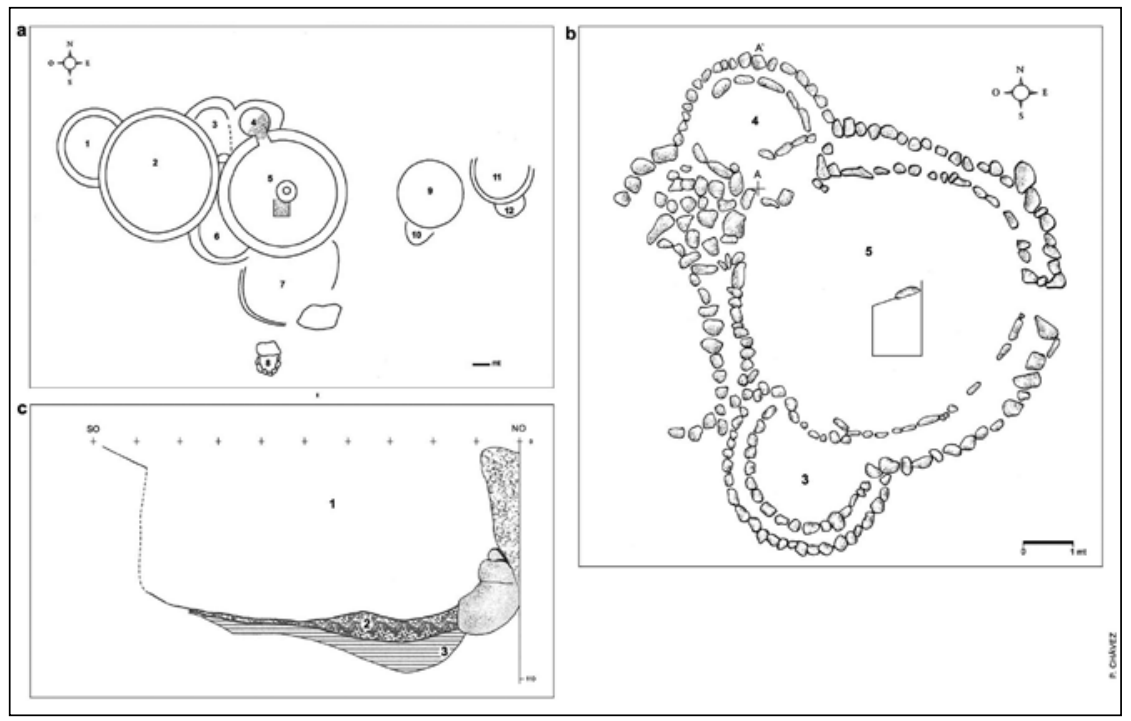

Figura 9. a) Croquis de Ghatchi 1 B; b) Recinto 4 y 5; c) Recinto 4, perfil oeste.

actividades domésticas de cocina y almacenamiento de alimentos (algarrobo, maíz y Chenopodium), para luego abandonar el lugar (Figura 8d). En cambio, con posterioridad, la mayor cantidad como diversidad cerámica que comprende tipos alisados y pulidos locales como de amplia circulación o foráneos, señala que la ocupación se extiende al Formativo Tardío, intensificándose, y desarrollándose actividades de cocina, almacenamiento, consumo y otras más especiales debido a presencia de cerámica decorada reutilizada y vasos negros pulidos del tipo Sequitor (Uribe 2006).

En consecuencia, el espacio construido habría adquirido una funcionalidad doméstica más compleja, seguramente concordante con una mayor estabilidad o permanencia, aunque la relativa escasez de cerámica todavía sugiere estadías cortas o temporales. De hecho, los restos de camélido y roedor son predominantes, aunque en baja densidad. El material lítico es aun más escaso, y a diferencia de los sitios anteriores, las materias primas más representadas son las obsidianas. Hay pocos artefactos, siendo los más abundantes las cuentas de mineral de cobre y silíceas blancas, pero sin perforadores. La escasez de instrumentos sugiere pocas actividades vinculadas a la adquisición y uso de instrumentos de piedra. No obstante, abundan los desechos de talla de obsidiana, seguidos por los de basalto y andesita, mientras que las silíceas son poco utilizadas a pesar de su disponibilidad, al contrario de la importancia que tienen en los otros sitios de Ghatchi. En suma, el comportamiento de Ghatchi ıA es algo distinto al resto de la quebrada, ya que aquí son las obsidianas las materias primas más frecuentes, lo que implica un cambio en la intención por la que se ocupa este espacio, optándose por materiales más finos. Si pensamos que la obsidiana negra podría estar viniendo de la alta Puna, se estaría accediendo a recursos provenientes del Noroeste Argentino, lo cual también está apoyado por la cerámica registrada, liderada por los tipos del Loa y Los Morros, de gran distribución espacial, aludiendo a amplios circuitos de movilidad y relaciones con la vertiente oriental circumpuneña. Esto, junto al escaso uso de materias primas líticas y el empleo de la obsidiana probablemente alóctona, afirman su asignación cronológica más tardía que la de los sitios de Ghatchi 2. En consecuencia, estas evidencias avalan la ocupación durante un momento medio y tardío dentro del Formativo que serían en gran parte compartidos con la cuenca del río Loa y las quebradas meridionales del Salar (Sinclaire et al. 1998; Carrasco 2006 Ms; Uribe 2006).

5. Ghatchi ${ }_{1} B$ (o2 Vil1). Conjunto de 12 estructuras circulares aglutinadas, de muros dobles con relleno, emplazadas unos $200 \mathrm{~m}$ aguas arriba de Ghatchi 1A, y con una bajada directa al río (Figura 9a). En superficie se registró 


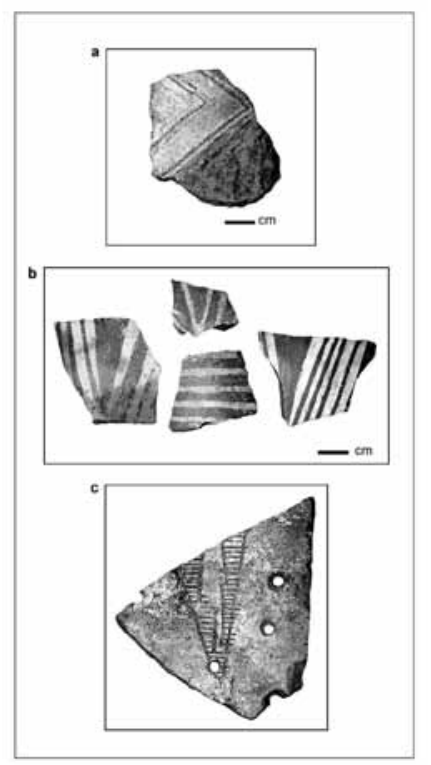

Figura 10. Cerámicas foráneas del Período Formativo presentes en San Pedro de Atacama: a) Pucara (Perú) en Larache Acequia; b) Vaquerías (Argentina) en Ghatchi ıB; c) Candelaria (Argentina) en Tchaputchayna.

cerámica policroma Vaquerías del Noroeste Argentino (Figura 10). Gracias a las excavaciones de los recintos 4 y 5 , se determinó que este sitio se construyó y utilizó durante el Formativo Tardío de acuerdo a una fecha de $1650 \pm 95$ AP (210-620 cal. DC) obtenida del piso del recinto 4 semihundido y abovedado (Figura 9b). El predominio de fragmentos de ollas, jarros y cántaros alisados como pulidos, locales y foráneos, indica diversas actividades domésticas de preparación, almacenaje y consumo de alimentos sólidos y líquidos. Junto a la presencia de vasos Sequitor, la cerámica Vaquerías señala el desarrollo de otras actividades menos comunes, si bien el conjunto lítico muestra un uso continuo aunque poco intenso del sitio, sugiriendo un estilo de ocupación "estanciera" (Adán 1999; Carrasco 2006 Ms).

El asentamiento es similar a Ghatchi IA en términos del uso de la localidad para fines distintos al aprovisionamiento de materias primas líticas. Los instrumentos más representados son las puntas de proyectil triangulares y pedunculadas con aletas, de obsidiana alóctona, las cuales pudieron ser terminadas en el sitio a partir de matrices ingresadas en estado avanzado, dadas las escasas canti- dades de desechos asociadas y a sus tamaños. Del mismo modo, la terminación de instrumentos (p.e., puntas, cuchillos, palas) fue una de las actividades más desarrolladas. Las puntas sugieren labores de caza, por lo que el sitio podría estar utilizándose como campamento ocasional. En este sentido, conformaría una unidad con Ghatchi IA debido a la continuidad tipológica y conductual de sus materiales, cuyas actividades parecieran estar centradas allí. Como en aquel sitio, la obsidiana es la roca más utilizada, con cientos de lascas y microdesechos, reiterando el interés por el uso de materias primas de mejor calidad y el vínculo con regiones alejadas, lo cual es avalado por la ocurrencia conjunta de cerámica Los Morros y Vaquerías que evidencian circuitos de movilidad y relaciones con la vertiente oriental circumpuneña, en particular con el Noroeste Argentino (Carrasco 2006 Ms; Uribe 2006).

Paralelamente, el mineral de cobre está presente en desechos y no cuentas u otro bien, destacando una pieza de cobre y un fragmento de cerámica con resto de mineral de cobre adherido, indicando el procesamiento de este mineral para obtener metal, más que para su elaboración artesanal en bruto. No obstante, también aparecen las cuentas de sílices y concha.

6. Calar (o2Vini7). La aldea de Calar se ubica en la primera terraza al este del río Vilama y consiste en un conjunto de 43 estructuras dispuestas en semicírculo alrededor de dos grandes plazas (Figura 11a), de donde Le Paige (1963) recuperó 20 tumbas de adultos y niños. Se conocía tan solo una fecha de $140 \pm 70 \mathrm{AC}$ sin calibrar (Llagostera 1988; Orellana 1988-89), que situaba al sitio en el Formativo Medio. En el descenso hacia el río existe una terraza agrícola, vinculada a las palas líticas que existen en el asentamiento.

El estudio arquitectónico realizado por Adán y Urbina (2007) identificó que las 43 estructuras no corresponden al mismo componente, pues son evidentes los eventos de reconstrucción del asentamiento. Entre estas, predominan las plantas circulares, subcirculares u ovales, seguidas por las plantas irregulares. Las estructuras rectangulares o subrectangulares son escasas aunque significativas, ya que las dos "canchas" ${ }^{5}$ centrales corresponden

\footnotetext{
5 Amplios espacios que pudieron ser utilizados como plazas o corrales.
} 


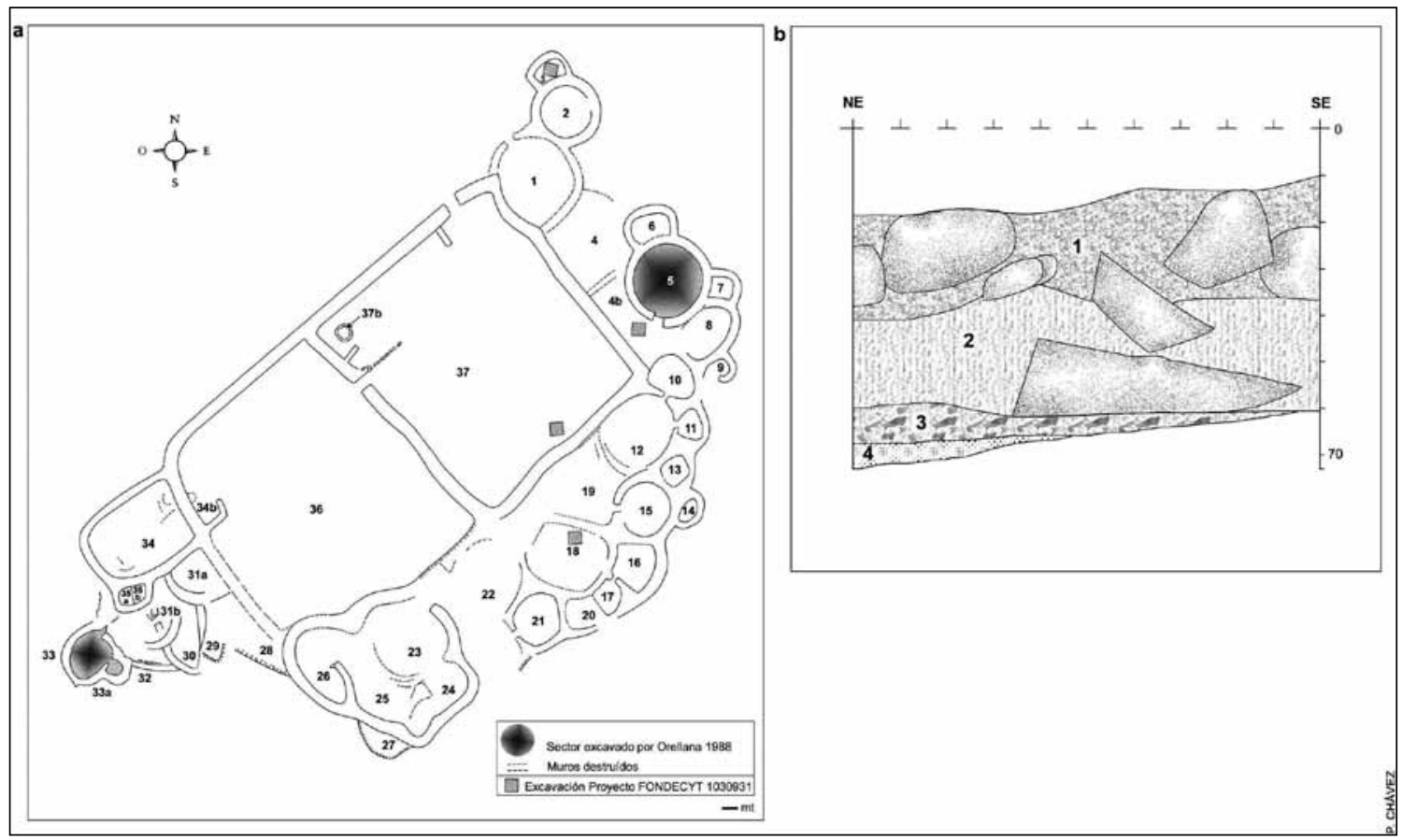

Figura 11. a) Plano de Calar (adaptado de Le Paige 1963); b) Recinto 3, unidad 1: perfil este.

a esta categoría. Los recintos fueron construidos con piedras, principalmente basalto, ignimbrita y turba como en Ghatchi 2 C. Los muros son predominantemente dobles con relleno, a veces con pilares para dar paso a la disposición de bolones, observándose también morteros cónicos integrados, así como diversos materiales conformando el relleno. A los recintos de planta circular, de entre 20 y 40 $\mathrm{m}^{2}$, se anexan otros de menores y variables dimensiones, distribuidos en torno a una plaza subrectangular (recinto 36); y a su vez, entre los conjuntos se disponen otros (interrecintos). Respecto a los momentos formativos, el asentamiento está menos afectado en el sector norte, en el cual se instalan los conjuntos anteriores. La sección sur, en cambio, estuvo más afectada por procesos de reconstrucción, habiendo allí un conjunto de una estancia con corral, "chiquero" o "enfermería" y habitación, donde se adicionaría la segunda "cancha" más tardíamente. En suma, la arquitectura de Calar corresponde a ocupaciones formativas y su característico patrón de recintos circulares en torno a estructuras centrales o patios, modalidad que privilegia las mesetas interfluviales y el uso de piedras de gran volumen del lugar, parte de una tradición arquitectónica ancestral en tierras atacameñas.
La excavación de cuatro recintos determinó un depósito que va de los 20 a los $63 \mathrm{~cm}$, con dos ocupaciones, la segunda correspondiente a reutilizaciones de la "cancha" como corral. En el recinto 3, ubicado más al norte en Calary no intervenido por ocupaciones posteriores, se fechó el inicio de la ocupación en 1810 \pm 55 AP (76-346 cal. DC) a los $63 \mathrm{~cm}$, la cual se asienta sobre una superficie arcillosa con restos de malaquita y un neonato humano cubierto por un mortero de hueco cónico fracturado, asociado a cerámica alisada del Loa, así como otros restos humanos posteriores (Figura 11b). Esta es la única estructura cuyo depósito alcanza tal profundidad, indicando una ocupación poco densa y poco alterada. Por lo tanto, el asentamiento habría sido empleado de manera muy pasajera y eventual. Si bien esta fecha acerca a Calar a los sitios Ghatchi $1 \mathrm{~A}$ y $1 \mathrm{~B}$, la aldea no es ocupada en el Formativo Tardío.

El conjunto cerámico indica la existencia de recintos habitacionales y contextos primarios, usados de manera exclusiva durante el Formativo, realizándose labores domésticas (p.e., preparación, almacenaje de alimentos y consumo de líquidos). La ocupación habría tenido un 


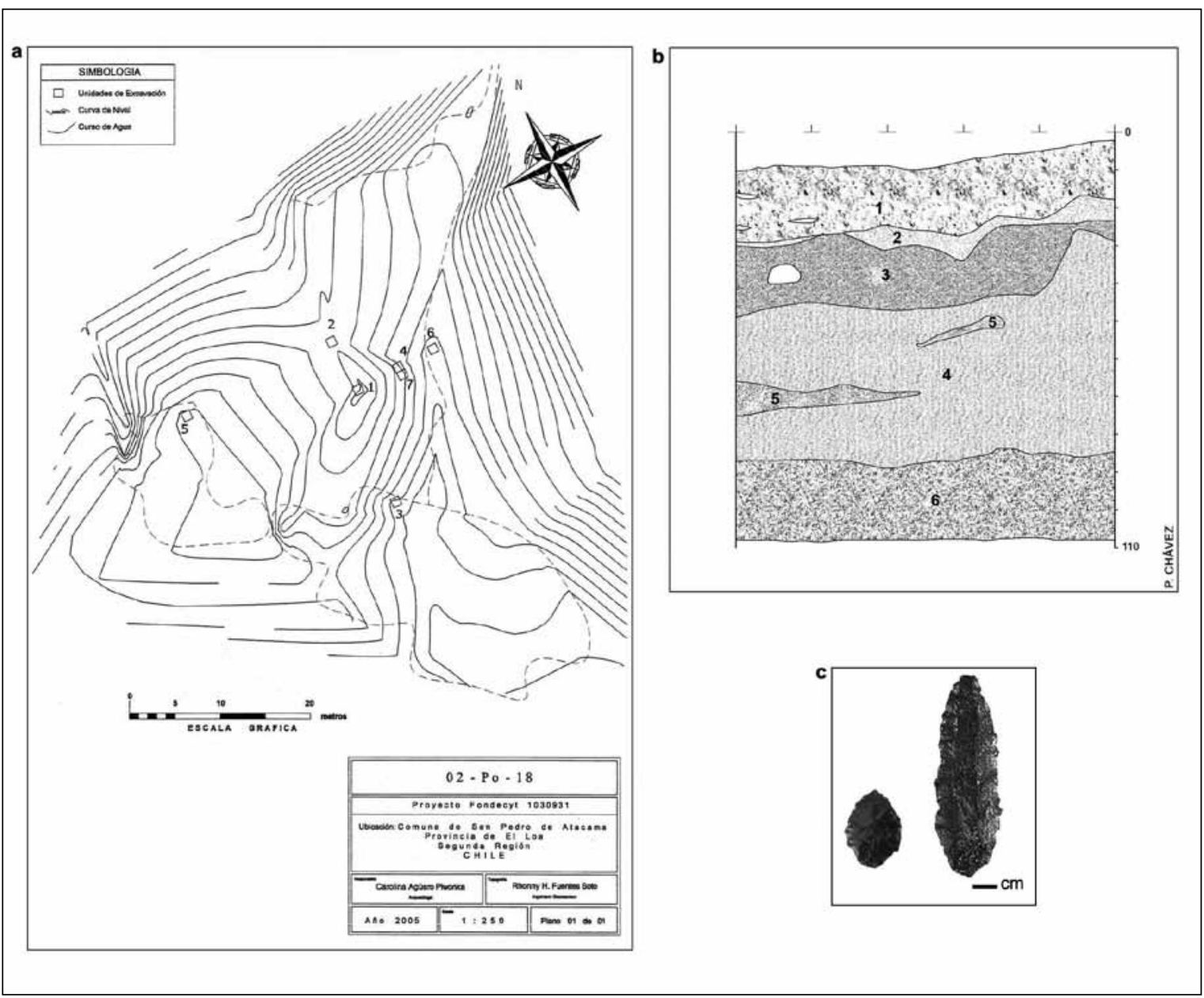

Figura 12. a) Plano de Poconche 18 (o2PO18); b) Unidad 4, perfil sur; c) Formas lanceoladas (unidad 4, capa 6, nivel 13 [80-90]).

carácter poco permanente o estacional, como lo señala la baja densidad de materiales líticos y su carácter de desechos primarios. Por lo mismo, la cerámica se emplearía para abastecerse por algún tiempo en el asentamiento, para después abandonarlo. Aparecen escasos restos de fauna como camélidos y chinchillidos, en distintos grados de combustión en el relleno de los muros, así como semillas carbonizadas de Prosopis y otras no comestibles. Por su parte, el material lítico es considerable. Las materias primas más utilizadas fueron las silíceas, basalto, andesita y obsidianas de origen local, teniendo el mineral de cobre una representación muy baja. Las rocas finas se eligieron para la talla bifacial, en tanto las gruesas indican desbaste inicial y obtención de matrices, al igual que en Ghatchi 2C y 2B. Entre los artefactos destacan las puntas de proyectil, los cuchillos, manos, machacadores, morteros de hueco cónico y algunos núcleos, donde las formas lanceoladas relacionan a Calar con momentos arcaicos, tal como planteaba Le Paige (1963), en tanto que la especialización vista en perforadores y palas de andesita lo vinculan al Formativo.

\section{Oasis de San Pedro de Atacama}

7. Poconche 18 (o2Po18). Se emplaza al sureste del actual ayllu de Poconche y corresponde a un asentamiento no estructurado, ${ }^{6}$ identificado a partir de la dispersión superficial de material lítico y cerámica. Las principa-

\footnotetext{
6 Tomamos esta categoría de Llagostera y Costa (1999).
} 
les concentraciones se localizan sobre un suave lomaje circundado por evidencias de escurrimientos de agua producidos por inundaciones estacionales (Figura 12a). En superficie, se observó cerámica Los Morros, bastantes desechos de talla y algunos artefactos entre los que destacan perforadores y cuentas en mineral de cobre y concha, junto a cierta diversidad de materias primas (Carrasco $2006 \mathrm{Ms}$ ).

La excavación de siete pozos de sondeo determinó que el sitio se ordena espacialmente en dos sectores: uno al oeste, con depósitos menos profundos y el más alterado por roedores (unidades 1, 2, 3 y 5); y otro con ocupaciones más profundas que se concentran hacia el este (unidades 4,6 y 7). Estas últimas unidades mostraron que el yacimiento fue ocupado por lo menos en dos oportunidades: una ocupación leve en las capas superiores, alteradas por procesos post depositacionales (roedores y lluvias); y otra más antigua entre 70 a $90 \mathrm{~cm}$ de profundidad (unidades 4, 6 y 7), bajo un estrato de arcilla que sella una capa de arena que contiene instrumentos formatizados como perforadores de sílices, cuentas de mineral de cobre, puntas de proyectil lanceoladas de basalto y obsidiana, además de desechos de talla, restos óseos entre los que destacan camélidos y Ctenomys fulvus, con huellas de combustión, lo que indica su caza y consumo, sobre todo en los niveles más profundos. Esta ocupación se fechó en la unidad 4 en $4568 \pm 87 \mathrm{AP}$ (3638-3097 cal. AC) (Figuras 12b y 12c).

Por otra parte, los depósitos superficiales y más marginales están alterados por la acción de roedores y presentan solamente ocupación asignable al Formativo Temprano por la exclusiva presencia de cerámica Los Morros hasta los 40 a $70 \mathrm{~cm}$ de profundidad. El material lítico es homogéneo en todos los sectores y profundidades, contándose 2.323 desechos y 112 instrumentos. Las materias primas más representadas son las silíceas y en menor proporción la obsidiana, basalto andesita y mineral de cobre, entre otras. Son frecuentes los perforadores y los objetos asociados como cuentas y restos descartados en el proceso de elaboración (p.e., buril y lezna), lo que permite suponer que su manufactura fue intensiva, recurrente y casi exclusiva, lográndose una producción especializada. En cambio, las puntas de proyectil, los raspadores y los cuchillos no están muy representados, lo que sugiere una escasa ejecución de tareas de caza y faenamiento. Con todo, las puntas lanceoladas y los perforadores son indicadores clave para su participación dentro de los complejos culturales del Arcaico Tardío que caracterizan las cuencas de Atacama, el Loa Medio y Superior (Druss 1978; Mena 1981; Núñez y Santoro 1988), extendiéndose hasta inicios del Formativo. Asimismo, el uso de basalto y obsidiana hace evidente la relación con la cuenca de Vilama durante esos momentos (Carrasco $2006 \mathrm{Ms}$ ).

Finalmente, por la superposición de estratos de arcilla estéril y arena con restos artefactuales, es probable que este sitio represente un asentamiento de uso estacional por parte de grupos de cazadores recolectores abocados a la recolección de algarrobo a fines del verano, posterior a la estación lluviosa que, en momentos previos a las ocupaciones periódicas, habría inundado el lugar.

8. Poconche 25 (02P025). El sitio está muy afectado por la erosión de escurrimientos superficiales de agua que deflacionaron los depósitos arqueológicos. Se emplaza al oeste de la duna de Poconche y al sur del sitio Sequitor (Le Paige 1974). Este autor indica que a unos $130 \mathrm{~m}$ al sureste del cementerio encontró un sitio habitacional, donde observó morteros, manos de moler y fragmentos de cerámica: "Entre los últimos hay varios tipos primitivos anteriores al rojo pulido, siendo fechado por $\mathrm{C}^{14}$ en Argentina alrededor del $800 \mathrm{AC}$, perteneciente a la Cultura San Francisco" (1974: 102). En superficie se observa bastante material dentro del cual destaca la cerámica Los Morros y cuentas discoidales de mineral de cobre. Se excavaron cuatro unidades en una transecta N-S, constatándose un depósito alterado por la acción aluvial y eólica que alcanzó los $25 \mathrm{~cm}$ con basuras domésticas que no fueron descartadas in situ. Se recuperó un total de 125 desechos y ocho instrumentos líticos, siendo las cuentas el artefacto más frecuente así como los perforadores de sílices, además de un fragmento de cona en granito.

9. Poconche 12 (02Po12). Se ubica al sureste del actual ayllu de Poconche, pocos metros al norte de Poconche 18. Posee un sector de cementerio que fue trabajado por Le Paige $(1957-1958,1964)$ y hoy cuenta con tres fechas de termoluminiscencia para cerámica Los Morros de 870 a 360 AC (Agüero 2005; Uribe 2006). El sector que consideramos en esta oportunidad abarca un área circunscrita por el depósito superficial de materiales formativos como microperforadores y cuentas, además de cerámica Los 

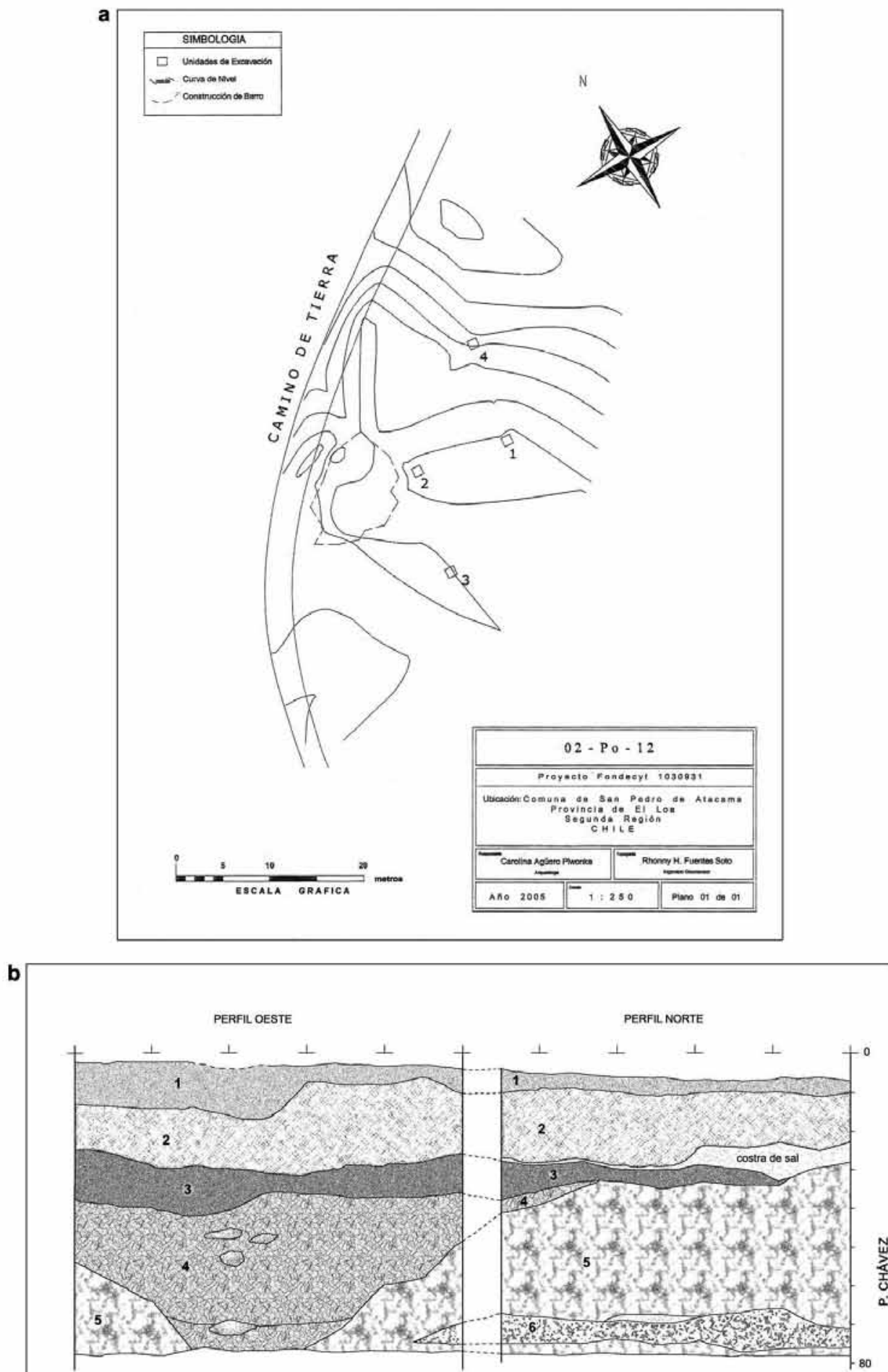

Figura 13. a) Plano de Poconche 12 (O2 $\mathrm{PO} 12)$; b) Unidad 3: perfiles oeste y norte. 
Morros (Figura 13a). La excavación de cuatro unidades determinó que el sitio fue ocupado densamente desde finales del Formativo hasta el período Medio, estando su núcleo en el sector de las unidades 2 y 3 . En la unidad 3 , el depósito alcanzó los $78 \mathrm{~cm}$ (Figura 13b), con una ocupación representada por un gran fogón en cubeta fechado en $1510 \pm 55$ AP (430-641 cal. DC), confirmando que la principal actividad comenzó a fines del Formativo.

Los fogones presentan ciertas concentraciones de restos de fauna y vegetales, con huesos grandes de camélido, fragmentos de moluscos (p.e., Turritela sp. y Strophocheilus oblongus), cánido y distintos roedores, junto a restos de maíz, algarrobo, Chenopodium (probablemente quínoa), Prosopis tamarugo y hoja de coca (Vidal 2006a y b). Esto hace suponer actividades de preparación de alimentos y consumo de recursos de los oasis, y posiblemente de las quebradas aledañas, además de aportes de la costa y el oriente. Se obtuvo un total de 691 desechos líticos y 94 instrumentos, donde el basalto y la andesita están bien representados, al igual que las obsidianas, mientras que el mineral de cobre es escaso. Es posible que estas materias primas hayan ingresado al sitio en forma de núcleos avanzados, para aquí obtener las matrices y terminar los instrumentos, aunque los pocos desechos sugieren que hay un énfasis en el uso doméstico y no en la elaboración de artefactos. Entre éstos destacan los perforadores y los núcleos, los primeros hechos en sílices locales; además hay buriles, leznas, puntas de proyectil triangulares con pedúnculo, cuchillos, cuñas y un raspador (Carrasco $2006 \mathrm{Ms})$.

Aunque la fecha asigna el sitio al Formativo Tardío, de acuerdo a los antecedentes y al registro de cerámica, principalmente Los Morros, en los niveles inferiores de las excavaciones la ocupación se habría iniciado en el Formativo Temprano. No obstante, por la abundancia de alfarería pulida y alisada característica de San Pedro, la mayor intensidad ocupacional ocurriría en el Formativo Tardío, y sobre todo en el período Medio, sugiriendo una transición entre las fases Sequitor y Quitor (Tarragó 1989). Cabe señalar que la cerámica formativa tardía, constituida por los clásicos ejemplares negros pulidos, se concentra en las unidades 1 y 4 , por lo que este sector podría ser el foco de la ocupación temprana del sitio, avalada por la gran cantidad de perforadores encontrados. En dichos momentos, los fragmentos de ollas y cántaros señalan contextos domésticos con preparación, almacenaje y consumo de alimentos, sólidos y líquidos, como lo sugieren los vasos Sequitor, aunque en momentos inmediatamente posteriores. Sin embargo, la actividad residencial habría sido bastante breve o acotada, dada la baja densidad de desechos y a su carácter primario.

10. Thhaputchayna (o2Be16). Se ubica al oeste del ayllu de Beter, en un plano al este del río San Pedro. Este sitio ha sido descrito por Le Paige (1974) y está compuesto por un sector de cementerio, otro de cultivos y una gran extensión de 30 túmulos habitacionales, que destaca por la abundancia y concentración de materiales superficiales, especialmente restos cerámicos y líticos. La erosión fluvial causada por el río ha afectado los contextos $y$, probablemente, ha deflacionado los depósitos arqueológicos, contribuyendo a la gran cantidad de restos en superficie. Se seleccionaron cinco túmulos con materiales formativos identificados por Le Paige, teniendo en consideración sus anotaciones, así como nuestros análisis de colecciones y de superficie (Agüero 2005). De este modo, se excavaron nueve unidades en los túmulos 2, 13, 20, 21 y 23 distribuidas a lo largo de $500 \mathrm{~m}$ de extensión N-S (Figura 14a). En general, los depósitos fueron poco potentes, salvo por un túmulo (20) con entierros y ofrendas correspondientes al período Medio; y otro (túmulo 23) con un buen depósito residencial del período Medio e Intermedio Tardío y un horno posterior, probablemente asociado a la ocupación de Beter I (también conocido como Pueblo de Indios). Este túmulo muestra una densa ocupación con al menos dos eventos en la capa 3 (Figura 14b), correspondientes a un área de habitación fechada en 865 \pm 100 AP (984-1296 cal. DC), entre las fases Coyo y Yaye-Solor (Tarragó 1989; Uribe 2002).

Se recuperaron 992 desechos y 87 instrumentos líticos. Las materias primas más frecuentes son los sílices, el basalto y la andesita, siendo también importantes el mineral de cobre y la obsidiana. La gran cantidad de desechos indica un énfasis en la terminación de instrumentos, que aquí están más representados por perforadores pequeños y cuentas. El resto de los instrumentos son poco frecuentes (p.e., raspadores, cuchillos, raederas, puntas de proyectil triangulares pedunculadas y convexas), indicando escasa actividad de caza y faenamiento. Otros artefactos bien representados son los molinos, distinguiéndose manos de moler, conas, metate, machacador, martillo y 


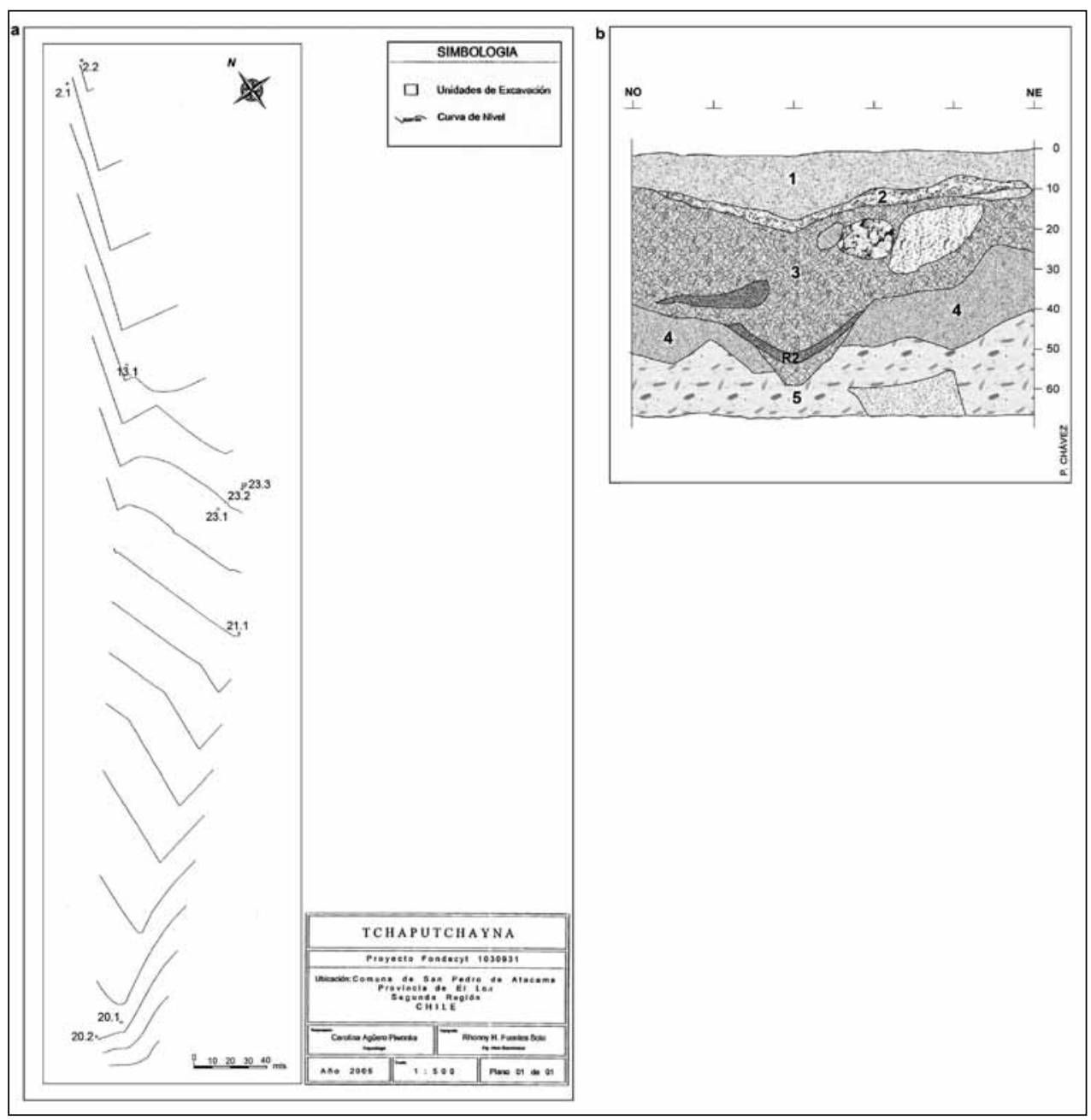

Figura 14. a) Plano de los sectores excavados en Tchaputchayna; b) Túmulo 23, unidad 1: perfil norte.

yunques, los que se asocian tanto al procesamiento de vegetales como a la molienda de mineral de cobre para elaborar cuentas o ser fundido, lo que es coherente con la presencia de objetos de metal. También se registraron fragmentos de palas. Toda esto apunta a que las actividades de uso y talla lítica estaban consistentemente especializadas en Tchaputchayna (Carrasco $2006 \mathrm{Ms}$ ).

En cuanto a la alfarería, se identificó cerámica Los Morros y Loa Café Alisado del Formativo Temprano que, junto al tipo San Pedro Rojo Pulido o Toconao, se vinculan al Formativo Medio, mientras que la presencia de vasos Sequitor y cerámica Candelaria del Noroeste Argentino aluden al Formativo Tardío. Como en Poconche
12, también se registra toda la alfarería pulida y alisada del período Medio, incluida la cerámica incisa de las fases Quitor y Coyo. Por último, aparece cerámica de la primera mitad del Intermedio Tardío y también ejemplares incaicos (Uribe 2002).

Esta situación permite concluir que hubo una ocupación continua desde el Formativo Temprano en adelante, pero con una clara concentración y auge durante el período Medio, declinando a inicios del Intermedio Tardío y diluyéndose en el Tardío. En relación con nuestro tema, durante el Formativo las ocupaciones serían poco intensas, muy dispersas y/o móviles, con una baja concentración poblacional. En este sentido, la baja densidad cerámica 


\begin{tabular}{|c|c|c|c|c|c|c|}
\hline Sitio & Unidad & Capa & Código & $\begin{array}{l}\text { Fecha calibrada } \\
\text { (2 sigmas })\end{array}$ & $\begin{array}{l}\text { Edad convencional } \\
\text { (AP) }\end{array}$ & Muestra \\
\hline Ghatchi $2 \mathrm{C}$ & $\mathrm{R}_{12} / 1$ & $3(35 \mathrm{~cm})$ & A-13938 & $4000-3350 \mathrm{AC}$ & $4885 \pm 125$ & Carbón \\
\hline Ghatchi $\mathrm{O}_{2} \mathrm{Vigo}$ & 1 & $\mathrm{~F}(67 \mathrm{~cm}$, sector este $)$ & A-14110 & 2204-1930 AC & $3685 \pm 50$ & Carbón \\
\hline Ghatchi $\mathrm{O}_{2} \mathrm{Vigo}$ & 1 & $\mathrm{~B}$ (nivel $3,23 \mathrm{~cm}$ ) & A-14114 & $1531-1392 \mathrm{AC}$ & $3190 \pm 55$ & Carbón \\
\hline Ghatchi 2B & $\mathrm{R}_{23} / 1$ & $3(46 \mathrm{~cm})$ & AA- 66972 & $400-200 \mathrm{AC}$ & $2245 \pm 35$ & Carbón \\
\hline Ghatchi 1A & $\mathrm{R}_{12} / 1$ & Rasgo $1(76-95 \mathrm{~cm})$ & AA- 68401 & $113 \mathrm{AC}-239 \mathrm{DC}$ & $1944 \pm 75$ & Hueso \\
\hline Calar & $\mathrm{R}_{3} / 1$ & $3($ nivel $10,60-65 \mathrm{~cm}$ ) & A-14111 & $76-346 \mathrm{DC}$ & $1810 \pm 55$ & Carbón \\
\hline Ghatchi 1 B & $\mathrm{R}_{4}$ & $2(84-88 \mathrm{~cm})$ & A-13936 & $210-620 \mathrm{DC}$ & $1650 \pm 95$ & Carbón \\
\hline Poconche18 & 4 & $4($ nivel $12,70-80 \mathrm{~cm})$ & AA- 68400 & $3638-3097 \mathrm{AC}$ & $4640 \pm 100$ & Hueso \\
\hline Poconche 12 & 3 & $4($ nivel $6,60 \mathrm{~cm})$ & A-14113 & $430-641 \mathrm{DC}$ & $1510 \pm 55$ & Carbón \\
\hline Tchaputchayna & $\mathrm{T}_{23} / 1$ & Rasgo $2(50 \mathrm{~cm})$ & A-14112 & 984-1296 DC & $865 \pm 100$ & Carbón \\
\hline Poconche 12 & Tumba Le Paige ¿? & & $\mathrm{UCTL}_{1611}$ & $870 \mathrm{AC}$ & $2870 \pm 260$ & Cerámica Los Morros \\
\hline Poconche 12 & Tumba Le Paige i? & & $\mathrm{UCTL}_{1612}$ & $845 \mathrm{AC}$ & $2845 \pm 290$ & Cerámica Los Morros \\
\hline Poconche 12 & Tumba Le Paige i? & & UCTL 1610 & $360 \mathrm{AC}$ & $2360 \pm 140$ & Cerámica Los Morros A \\
\hline Yaye C. de Toros ${ }^{7}$ & $\operatorname{Tr} 3, \mathrm{~m} 2$ & Nivel 10 & UCTL 1614 & $380 \mathrm{AC}$ & $2380 \pm 200$ & Cerámica Los Morros B1 \\
\hline Yaye C. de Toros & $\operatorname{Tr} 3, \mathrm{~m} 2$ & Nivel 10 & $\mathrm{UCTL}_{16} 6_{13}$ & $460 \mathrm{AC}$ & $2460 \pm 240$ & Cerámica Loa Café Alisado \\
\hline Yaye C. de Toros & $\operatorname{Tr} 1, \mathrm{~m} 10$ & Nivel 10 & UCTL 1615 & $640 \mathrm{AC}$ & $1360 \pm 130$ & Cerámica Sequitor \\
\hline
\end{tabular}

Tabla 1. Fechas C14 y TL obtenidas de asentamientos de oasis de San Pedro de Atacama y quebrada de Vilama.

pareciera ser común para el período, sobre todo en el Formativo Temprano, en los sitios habitacionales de las quebradas, pero aún más en los oasis. Al comparar las frecuencias de Tchaputchayna y Poconche con Calar, Ghatchi u otros sitios de Puripica y Tulan (Uribe 2006), difícilmente las muestras superan el centenar de fragmentos. Por otro lado, en los oasis este material tiende a depositarse en los estratos inferiores de los sitios, en este caso a partir de los $40 \mathrm{~cm}$ de profundidad, distinguiéndose ejemplares exclusivamente del Formativo Temprano; mientras que sobre los $40 \mathrm{~cm}$, se asocian a evidencias del Formativo Tardío, donde se agregan los tipos San Pedro Rojo y Negro Pulido correspondientes a las fases funerarias Toconao y Sequitor.

En suma, esta secuencia ocupacional continua desde el Formativo Temprano apoya la idea de un patrón de asentamiento de pequeña escala, disperso y/o de alta movilidad, que recuerda lo observado en Poconche como también en Calary Ghatchi, aunque volviéndose aún más efímero en los oasis, quizás por una ocupación marcadamente estacional. Luego de estos eventos, la ocupación se desarrollaría preferentemente en el período Medio, expe- rimentando un notable auge en las fases Quitor y Coyo, diluyéndose hacia los primeros momentos del Intermedio Tardío y muy débil durante el Tardío.

\section{* Resultados y discusión}

El estudio superficial y estratigráfico de estos 10 asentamientos de quebradas y oasis junto a 16 nuevos fechados absolutos (Tabla 1), nos permiten avanzar con datos de primera mano en el conocimiento de la historia cultural de San Pedro de Atacama durante el período Formativo.

Los datos indican que en la quebrada de Vilama, los principales asentamientos se emplazaron en el segmento Ghatchi-Calar, donde hay antecedentes de una importante ocupación arcaica en Ghatchi 2C, Ghatchi o2Vigo y, probablemente, la primera ocupación bajo los muros de Ghatchi 2B.

7 Yaye Corral de Toros fue excavado por Hermosilla y colaboradores (2003 Ms) en el marco de una Declaración de Impacto Ambiental (DIA). 
Este sistema integraba amplias esferas de circulación, según el hallazgo de restos de moluscos y pescado, observándose el predominio de la caza de camélidos y las actividades relacionadas, donde el arte rupestre de Ghatchi o2Vigo y las fechas obtenidas indican el tránsito hacia el Formativo (Montt 2006a y b).

Estos sitios, además, están relacionados a través de distintas evidencias con los complejos contemporáneos de Puripica y Tulan así como con el de Chiu Chiu (Núñez 1981; Núñez y Santoro 1988; Núñez et al. 1999). ${ }^{8}$

Además, las conductas agresivas de los camélidos relacionadas con la reproducción (González 2002) que se observan en las representaciones de Ghatchi O2Vigo (Montt $2006 a$ y b), sugieren que aquí ya se ha iniciado el proceso de domesticación, pues como señala Olivera (1997), los pastores tempranos debieron poner en práctica estrategias para controlar dichos comportamientos y asegurar la reproducción y el equilibrio interno de los rebaños.

Posteriormente, los asentamientos del Formativo Temprano de Ghatchi $2 \mathrm{~B}$ y sectores de Ghatchi $2 \mathrm{C}$ se desplazan hacia al norte, anunciando el posterior nucleamiento que ocurre en la meseta de Ghatchi 1, aprovechando la misma locación y su cercanía a vertientes, fuentes de aprovisionamiento lítico y vegas debido a la dependencia humana de los camélidos. En el conjunto central de Ghatchi $2 \mathrm{C}$, los depósitos efímeros y la escasez de cerámica indican que sus contextos primarios serían el producto de una ocupación muy ligera, poco permanente y móvil, en donde se presentan los primeros espacios construidos relacionados con actividades de congregación social. En este sentido, las ocupaciones en los recintos son muy débiles, de manera similar a lo observado en Ghatchi $2 \mathrm{~B}$. Luego, se produciría una mayor centralización y fortalecimiento de la presencia transicional o del Formativo Medio en Ghatchi 1A, al igual que en Calar, con tendencia a una mayor estabilidad a juzgar por los depósitos y la diversidad funcional de la cerámica, aunque todavía de carácter semipermanente o estacional.

En efecto, al parecer en estos sitios ya hay sociedades pastoriles a pequeña escala, con movilidad más restrin-

\footnotetext{
8 Lamentablemente, no podemos ser más precisos en estas relaciones ya que no tuvimos acceso a las colecciones líticas de Puripica 1.
}

gida, y apoyadas en la caza y recolección, aunque aún la inestabilidad del nuevo modo de vida es contrastante con la mayor estabilidad mostrada por los densos depósitos arcaicos de Ghatchi $2 \mathrm{C}$ y de Ghatchi o2Vigo.

En Ghatchi 1A, el inicio de ocupación y la construcción de los recintos ocurre en el Formativo Medio, continuando a una etapa tardía cuando se construye Ghatchi $1 \mathrm{~B}$ unos cientos de metros más al norte. Los tipos alisados y pulidos locales junto a ejemplares de amplia circulación o foráneos como Los Morros, Loa Café Alisado, Sequitor y Vaquerías, en asociación a obsidiana alóctona, indican que Ghatchi $1 \mathrm{~A}$ y Ghatchi $1 \mathrm{~B}$ estuvieron integrados en amplias esferas de interacción que abarcaban la Subregión del río Salado, el Noroeste Argentino y los oasis de San Pedro de Atacama.

Así, en estos momentos habría ocurrido una intensificación de la presencia humana, y el espacio construido habría adquirido una funcionalidad doméstica más compleja en la medida que avanzaba el proceso formativo en la región y la consecuente centralización de actividades residenciales en el lugar, apoyadas en el acceso al algarrobo, chañar, maíz, Chenopodium y calabaza (incluso pirograbadas), recuperadas en Ghatchi 1A y Calar (Vidal 2006a). Las especies vegetales de los oasis, por lo tanto, estarían en uso ya desde el Formativo Medio, extendiéndose al Formativo Tardío, aunque todavía con una marcada estacionalidad del patrón de asentamiento.

Arquitectónica y cronológicamente Calar es muy similar a Ghatchi 1A, en particular por la ritualización de los espacios domésticos a través del entierro de niños bajo o cerca de los muros, a la vez que coherente con sus fechas medias y tardías. Sin embargo, su ocupación se remontaría al Formativo Temprano de acuerdo a sus contextos líticos y cerámicos. Por lo tanto, el cementerio excavado por Le Paige (1963) en una de las "canchas" de Calar sería posterior al abandono del asentamiento y se relacionaría más bien con los oasis san pedrinos, a juzgar por los contextos típicos de la fase Sequitor, que se relacionarían con los canchones de cultivo existentes cerca del río. De este modo Calar, a pocas horas de marcha de San Pedro, durante el Formativo Medio habría sido habitado por poblaciones de los oasis, y en el Formativo Tardío bien pudo haber estado bajo el control de ellas sin que necesariamente se hayan establecido allí, a modo de es- 
tancias que aprovechan el lecho y márgenes amplios del río, junto con sus algarrobos y chañares. Su ubicación estratégica permitiría el acceso a espacios y recursos diferentes, ya sea en forma directa o a través del intercambio, consistente con su emplazamiento en plena ruta de conexión con el actual altiplano boliviano (Nielsen 2006; Pimentel 2008).

Todo lo anterior permite hipotetizar que en la medida que avanzaba el Formativo, tanto Calar como Ghatchi iA pasaron a constituir asentamientos-ejes, incluso antes del inicio de la ocupación de Tulor 1 , fechado en $380 \pm 160$ AC-125£130 DC (Barón 1986) y 200-245 cal. DC (Llagostera et al. 1984). Sus contextos similares a los de los oasis junto a su ocupación esporádica o estacional, sugieren que Calar fue durante el Formativo Medio el punto que insertó a San Pedro en el tráfico hacia Bolivia y el Loa. Posteriormente, se privilegiarían las relaciones con el Noroeste Argentino que cambiaría la orientación de la ruta, controlada desde los oasis.

De esta manera, parece probable que las poblaciones de los oasis no hayan participado activamente en el uso de estas rutas hasta entrado el Formativo Medio, habiendo por el contrario una evidente movilidad en un sentido opuesto, es decir, desde la alta Puna y/o Loa Superior hacia los sitios piepuneños cercanos a San Pedro. En tal sentido, parece aplicable lo planteado por Olivera respecto a que:

"[...] la llama de los sitios pastoriles tempranos corresponde a una variedad proveedora de carne y lana y menos especializada en el transporte [...] mientras que la implementación de los animales cargueros fue incrementándose a partir de los 500 a 1000 $A P^{\prime \prime}(1997: 118)$.

Según las fechas de Calar y Ghatchi iA esto ocurriría, con seguridad, durante el primer siglo de nuestra era.

Ahora, bajando a los oasis, Poconche 18 permite sostener que en este ámbito las ocupaciones formativas también están precedidas por recurrentes incursiones estacionales arcaicas que desarrollaban actividades especializadas junto a otras de tipo doméstico, confirmando un ancestral interés por los recursos que aquí se presentaban. La especialización que se observa en su material lítico refiere a un asentamiento semipermanente de tareas específicas. Las ocupaciones posteriores en el sitio destacan por la frecuencia de perforadores, que evidencian un desarrollo intensivo, prácticamente exclusivo de dicha actividad, aunque combinada con actividades más domésticas o residenciales como consumo de alimentos y terminación de instrumentos líticos, sin que se registren prácticas de molienda. El empleo de basalto y obsidianas que, con altas probabilidades provienen de la cuenca de Vilama, junto a la contemporaneidad de las fechas de este sitio con el sector temprano de Ghatchi $2 \mathrm{C}$, afirman una temprana complementación entre ambas zonas, quizás estacional.

Tal vigencia de la ancestral complementariedad en el uso de los bordes del Salar de Atacama, se remonta a las evidencias de Tambillo y sus quebradas adyacentes (Núñez 1992; Núñez et al. 1999). Sin embargo, en los oasis esta situación no había sido registrada hasta ahora.

Las primeras ocupaciones con cerámica en el oasis se aprecian en Poconche, enmarcándose dentro del Formativo Temprano y Tardío, extendiéndose hacia el período Medio en Poconche 12, aunque solo en la fase Quitor. Por su parte, Poconche 25 se comporta de manera similar a Poconche 18, siendo las actividades de confección de cuentas las que marcan la funcionalidad del asentamiento, situándose dentro del Formativo Temprano.

También Poconche 12 muestra un patrón similar a Poconche 18 , aunque en continuidad con una intensa ocupación durante el período Medio, que muestra espacios residenciales con acumulación de desechos primarios y secundarios resultantes de actividades tanto domésticas como funerarias. Sin embargo, entre el Formativo Temprano y Tardío se aprecian ocupaciones más esporádicas y poco intensas que recuerdan a Calar y a Ghatchi, aunque aún más livianas en los oasis, quizás por su marcada estacionalidad.

Sin duda, esta situación es la que se transforma en los oasis durante el Formativo Tardío y especialmente durante el período Medio, concentrándose allí las poblaciones y prácticamente desapareciendo de las quebradas (Agüero 2005; Uribe 2006), lo que contradice lo planteado por Núñez (2005).

En suma, los sitios de Poconche muestran una presencia continua desde antes del Formativo Temprano, configurando una ocupación con fines habitacionales probable- 
mente de arquitectura perecedera, donde los materiales diagnósticos tienden a concentrarse en los niveles inferiores de los depósitos, ${ }^{9}$ con una baja concentración poblacional, muy dispersa y/o estacional.

Finalmente, Tchaputchayna también mostraría una ocupación continua desde el Formativo Temprano en adelante, pero con una clara concentración y auge en el período Medio, declinando a inicios del Intermedio Tardío y diluyéndose en el período Tardío. Asimismo, tanto en el Formativo Temprano como Tardío, las ocupaciones serían poco significativas, muy dispersas y con una baja concentración poblacional, como sucede en Poconche y Vilama. Esta tendencia es confirmada en Tchaputchayna y en Poconche 12 por los perforadores de reducido tamaño y puntas triangulares pedunculadas que muestran una intensificación en los momentos avanzados del Formativo. Por otro lado, el uso de la obsidiana negra foránea utilizada en la confección de puntas de proyectil, supone una ocupación más tardía de los asentamientos como Ghatchi 1A y 1 B.

Las ocupaciones esporádicas o poco intensas de estos sitios se mantendrían hasta el Formativo Tardío, desarrollándose actividades poco permanentes, por un pequeño o moderado contingente poblacional, quizás familiar y móvil, pero distinguiéndose que mientras se abandonan los sitios tempranos de las quebradas en esta época (p.e., conjunto estructural central de Ghatchi $2 \mathrm{C}$, Ghatchi $2 \mathrm{~B}$ y la aldea de Calar), en los oasis se vislumbran transformaciones sustanciales, denotando un notable crecimiento y estabilidad, precedido por el cambio estilístico de la alfarería que muestra el auge de la cerámica monocroma Rojo y Negra Pulida de las fases Toconao-Sequitor-Quitor, hasta la fase Coyo en Tchaputchayna.

Solo considerando que la mayoría de los cementerios del período se concentra en los oasis (Cucuter, Larache, Larache Acequia, Poconche, Sequitor Alambrado Acequia, Sequitor Alambrado Oriental, Solor 3, Solor 6 y Tchaputchayna), con un notable auge hacia el Formativo Tardío junto al desplazamiento hacia la parte alta o norte de San

\footnotetext{
9 La evidencia arqueológica en los oasis, y en especial, para el Formativo, ha estado afectada de manera drástica por una serie de procesos post depositacionales, particularmente aluviales, que dificultan la investigación.
}

Pedro, se infiere un sostenido proceso de estabilidad e intensidad ocupacional de este espacio (Llagostera y Costa 1999; Agüero 2005).10

En estos momentos es cuando se evidenciaría un distanciamiento entre las tradiciones culturales de quebradas y oasis, adquiriendo un creciente predominio los oasis de San Pedro, apoyados en sus recursos vegetales silvestres, una incipiente horticultura y una promisora industria artesanal, que incluye cerámica, madera y metalurgia.

Los materiales hallados tanto en sitios habitacionales como funerarios, muestran actividades diversificadas, destacando el aprovechamiento y procesamiento bastante especializado de los árboles (algarrobo y chañar) y sus frutos. De hecho, uno de los aspectos más notables en torno a las actividades que se realizan es la escasez de evidencias que sustenten el desarrollo agrícola de los oasis durante el período, permitiendo a lo sumo plantear el desarrollo de horticultura (Vidal 2006a y b).

Por lo tanto, es posible que jamás se haya realizado agricultura de maíz en este ámbito, sino hasta tardíamente (Uribe y Adán $2003 \mathrm{Ms}$ ). Más aún, son elocuentes las observaciones de Costa y colaboradores (2004), que indican que antes de la interacción con Tiwanaku, las poblaciones locales tenían menor estatura y las caries, desgaste dental y pérdida de piezas en vida fue mayor, evidenciando menor acceso al recurso cárneo y mayor consumo de granos duros y harinas de grano grueso (Agüero 2005). De este modo, para los oasis, la base alimentaria habrían sido los recursos locales recolectados, con un suplemento menor de carnes, pero con cierta importancia del camélido, por lo que suponemos que aunque el pastoreo fue una actividad autónoma de las quebradas, hubo cierto nivel de crianza con fines alimentarios y un uso complementario de estancias como Calar, en la cuenca de Vilama.

De este modo, las características del asentamiento sugieren ocupaciones estacionales, vinculadas a la recolección de los frutos de algarrobo y chañar, que paulatinamente se van haciendo más estables, sustentando el desarrollo de la horticultura, pues las evidencias de plantas domésticas no son abundantes, siendo más evidentes a partir

\footnotetext{
${ }^{10}$ Para una posición opuesta a nuestros planteamientos, ver Núñez (2005).
} 
del Formativo Tardío con escasos restos de maíz y semillas de Chenopodium (Vidal 2006a y b)."1

Respecto al tráfico caravanero y al pastoreo, el estudio de su materialidad señala que en los oasis no existe mayor evidencia, por lo que al igual que la agricultura, tampoco constituye una característica de ellos (Cases $2005 \mathrm{Ms}$; Vidal 2006a y b). Los bienes de intercambio presentes en los oasis son eminentemente locales, con solo un puñado de productos foráneos, tanto del Pacífico como de la vertiente oriental circumpuneña (restos marinos y caracoles de agua dulce de valles argentino-bolivianos -Strophocheilus oblongus - y piezas Candelaria).

En este contexto, destaca la especialización de los oasis en la confección de cuentas de mineral cobre, el surgimiento local de las cerámicas pulidas, una creciente industria de maderas vinculada a la concentración de herramientas como de objetos metálicos, sugiriendo una especialización en estos rubros que hacia la mitad y final del Formativo caracterizarán a los oasis de San Pedro. Por su parte, el hecho de que en la cuenca del Vilama se produzca el aprovisionamiento de materias primas y matrices líticas hacia otras localidades junto con el acceso a animales, y que los sitios de los oasis sean receptores y consumidores de ellos, evidencia una relación de complementariedad donde aquellos pudieron ser trocados por los objetos producidos aquí. Así, en el Formativo Tardío los indicadores funerarios muestran individuos con tembetá, hachas, mazos e implementos para consumir alucinógenos, indicando que algunos sectores se están desvinculando del ámbito de la subsistencia, gracias al excedente producido por la dinámica formativa entre quebradas y oasis.

\section{* Las sociedades formativas de \\ San Pedro de Atacama: palabras finales}

Los contundentes datos que hemos obtenido y su análisis, nos permite afirmar que las sociedades formativas de San Pedro tienen antecedentes en ocupaciones arcaicas, que

11 Sería sumamente interesante comprobar un mayor consumo de maíz, en forma de bebida alcohólica, a través de estudios bioantropológicos. Lamentablemente los cuerpos humanos del período Formativo de los oasis no se conservan de la manera que nos gustaría. hasta ahora no habían sido documentadas, sino únicamente en las quebradas altas y $30 \mathrm{~km}$ al sur, en Tambillo.

Las evidencias iniciales del Formativo se remontan al primer milenio AC en la quebrada de Vilama y los oasis bajos, siendo su articulación muy fuerte hasta los inicios de la era; mientras que hacia el 100 DC ambos desarrollos tienden a separarse, lo que interpretamos como el tránsito desde una economía complementaria basada en prácticas de caza y pastoreo y recolección, a otra sustentada en recolección, horticultura y producción artesanal.

\section{Recapitulando, proponemos:}

1) Una Fase 10 Temprana (1200-350 AC), análoga a la fase Tilocalar propuesta por Núñez (1992, 1994), especialmente evidente en las quebradas del Salar y vinculada con la Fase Vega Alta del Loa Medio (Pollard 1970; Benavente 1982), equivalentes en su orientación económica transicional, pero discutibles, ya que no se trataría de sociedades agropastoriles con una clara jerarquización social.

En este contexto, los grupos de Ghatchi-Calar de marcada naturaleza arcaica, están tempranamente articulando un amplio territorio, posicionándose en un espacio estratégico respecto a los recursos locales como a las vías de circulación, movilidad y acceso entre la Puna, las quebradas altas del río Salado y los oasis de San Pedro.

Sus asentamientos no necesariamente actúan como centros aldeanos propiamente tales, sino más bien con un carácter social, simbólico e identitario como el que manifiestan construcciones ceremoniales al sur del Salar (Núñez 1994). Esta fase está nucleada en los sitios quebradeños de Ghatchi 2, pero incorpora a Poconche y Tchaputchayna en los oasis.

2) Luego, en una Fase 2 o Media ( 350 AC-10o DC), ocurre una creciente estabilización y permanencia poblacional hacia la cuenca del Salar, construyéndose aldeas como Calar, Ghatchi 1A y Tulor, e inaugurando cementerios en los oasis, como Larache Acequia y Sequitor Alambrado Acequia, contemporáneamente a Toconao Oriente (Agüero 2005).

En este sentido, coincidimos con Tarragó (1989) en que el cambio estilístico alude a un fortalecimiento de la identi- 
dad local, pero no se caracteriza por "poblaciones agrarias estables". Al contrario, por un lado la recolección arbórea se refuerza en los oasis, mientras que prácticas de pastoreo se concentran en Calar, y recién se iniciaría la horticultura de maíz. A esta situación se suma la emergente especialización productiva de manufacturas para articular el intercambio entre ambos espacios, abriendo las posibilidades de un promisorio tráfico a larga distancia.

No obstante, lo anterior no apoya una configuración agropastoril del sistema de caravanas (Núñez y Dillehay 1979 [1995]), especialmente, porque lo que se observa es un paulatino desplazamiento del sistema económico cazador y pastoril a otro con énfasis recolector y horticultor, promoviendo una sobreproducción y desarrollo de manufacturas para mantener el control sobre la complementariedad del propio entorno a través del intercambio interno.

3) Finalmente, la Fase 3 o Tardía (100 AC-500 DC) sería análoga a Sequitor (Tarragó 1989), en cuanto ocurre el mayor crecimiento y la sedentarización circunscrita a los oasis de San Pedro de Atacama, convirtiéndose en la base del período Medio.

Poconche y Tchaputchayna son los principales referentes junto a Coyo 12, Coyo Oriente, Larache, Sequitor Alambrado, Sequitor Oriental y Solor 6 (Agüero 2005). A la par, se abandonarían algunos importantes asentamientos previos, como Calar y Tulor 1, demostrando la restricción hacia el centro y norte de San Pedro de Atacama (Llagostera y Costa 1999), indicando definitivamente una circunscripción social y geográfica que requería especializar el sistema económico local y el intercambio a larga distancia.
Lo anterior se relacionaría con una mayor interacción con el Noroeste Argentino y un posterior tráfico "especializado" (Nielsen 2006).

En definitiva, no fue la producción agrícola ni el tráfico de caravanas los que jugaron el rol central en la complejidad atacameña que surge durante el Formativo, sino más bien la ancestral dinámica arcaica en relación con los recursos locales de las quebradas y oasis, donde los frutos y maderas de algarrobo y chañar llevarían a San Pedro a convertirse en un atractivo centro económico, social y cultural.

Agradecimientos A FONDECYT por financiar el Proyecto 1030931: "Registro y cronología del Período Formativo en los oasis de San Pedro de Atacama”. A los colegas Patricia Ayala, Ulises Cárdenas, Carlos Carrasco, Bárbara Cases, Dánisa Catalán, María Antonietta Costa, Josefina González, Indira Montt, Gonzalo Pimentel, Simón Urbina y Alejandra Vidal, quienes integraron la investigación. A Rolando Ajata, Susana Dip, Magdalena García, Naotoshi Ishiki, Virginia McKrostie, Pablo Méndez-Quirós y Patricio de Souza, quienes colaboraron en las últimas campañas de terreno junto a los amigos Belisario Cruz, Jimena Cruz, Claudia del Fierro, Wilfredo Faúndez, Sergio Puca, Cecilia Ramírez, Félix Ramos, César Ramos y Justina Romero. A don Gerardo Ramos por ayudarnos en Tchaputchayna con un "convido" o ritual, y a don Eleuterio Romero ( $\dagger$ ) por acogernos durante la fiesta de San Antonio. Finalmente, agradecemos a Carlos Aschero, José Berenguer e Iván Muñoz quienes hicieron valiosos comentarios y sugerencias al manuscrito y consiguientemente contribuyeron a mejorarlo sustancialmente.

\section{* Referencias citadas}

ADÁN, L. 1999. Aquellos antiguos edificios. Acercamiento arqueológico a la arquitectura prehispánica de Caspana. Estudios Atacameños 18: 13-33.

ADÁN, L. y S. URBINA, 2007. La arquitectura formativa en San Pedro de Atacama. Estudios Atacameños 34: 7-30.

ADÁN, L., S. URBINA y M. URIBE, 2007. Arquitectura pública y doméstica en las quebradas de Pica-Tarapacá: Asentamiento y dinámica social en el Norte Grande de Chile (900-1450 DC). En Procesos sociales prehispánicos en el sur andino. La vivienda, la comunidad y el territorio, A. Nielsen, C. Rivolta, V. Seldes, M. Vázquez y P. Mercolli (Eds.), vol. 1, pp. 183-206. Colección Historia Social Precolombina. Editorial Brujas, Córdoba.

AGÜERO, C. 2005. Aproximación al asentamiento humano temprano en los oasis de San Pedro de Atacama. Estudios Atacameños 30: $29-60$. 
AGÜERO, C., P. AYALA, M. URIBE, C. CARRASCO y B. CASES, 2006. El período Formativo desde Quillagua, Loa Inferior (norte de Chile). En Esferas de interacción prehispánicas y fronteras nacionales modernas. Los Andes Sur Centrales, H. Lechtman (Ed.), pp. 73-125. Instituto de Estudios Peruanos, Lima.

BARÓN, A. M. 1986. Tulor: Posibilidades y limitaciones de un ecosistema. Chungara 16-17: 149-158.

BENAVENTE, A. 1982. Chiu Chiu 200: Una comunidad pastora temprana en la provincia del Loa (II región). Actas del IX Congreso Nacional de Arqueología, pp. 75-94. Museo Arqueológico de La Serena, La Serena.

BERENGUER, J., A. DEZA, A. ROMÁN y A. LLAGOSTERA, 1986. La secuencia de Myriam Tarragó para San Pedro de Atacama: Un test por termoluminiscencia. Revista Chilena de Antropología 5: 17-54.

CARRASCO, C. 2006 Ms. Materialidad lítica de sitios habitacionales formativos de la quebrada de Vilama y oasis de San Pedro de Atacama. Informe para Proyecto FONDECYT 1030931, Santiago.

CASES, B. 2005 Ms. Caravanas en los oasis y quebradas de San Pedro de Atacama durante el período Formativo. Informe para Proyecto FONDECYT 1030931, Santiago.

COSTA, M. A. 2004 Ms. Informe bioantropológico del material osteológico de Vilama. Informe para Proyecto FONDECYT 1030931, Santiago.

COSTA, M. A., W. NEVES y M. HUBBE, 2004. Influencia de Tiwanaku en calidad de vida biológica de la población prehistórica de San Pedro de Atacama. Estudios Atacameños 27: 103116

DRUSS, M. 1978. Enviroment, subsistence economy and settlement pattern of the Chiu Chiu Complex (ca. 2700 to 1600 BC) of the Atacama Desert, Northern Chile. Ph. D. Thesis, Columbia University, Columbia.

GONZÁLEZ, J. 2002. Etología de camélidos y arte rupestre de la subregión río Salado (norte de Chile, II región). Estudios Atacameños 23: 23-32.

2006 Ms. Arqueofauna de la quebrada de Vilama y oasis de San Pedro de Atacama. Informe para Proyecto FONDECYT 1030931 , Santiago.

HERMOSILLA, N., R. SÁNCHEZ y M. URIBE, 2003 Ms. Proyecto Hotel en ayllu de Yaye, San Pedro de Atacama, II Región:
Ampliación de Línea base sitio "Corral de Toros". Informe para AMBAR S.A., Santiago.

LE PAIGE, G. 1957-1958. Antiguas culturas atacameñas en la cordillera chilena. Anales de la Universidad Católica de Valparaíso 4-5: 15-144.

1963. Ghatchi y su zona. Revista Universitaria, Año XLVIII, pp. 177-193.

1964. El precerámico en la cordillera atacameña y los cementerios del período Agroalfarero de San Pedro de Atacama.Anales de la Universidad del Norte 3.

1974. El yacimiento de Tchaputchayna. Estudios Atacameños 2: $59-74$.

LLAGOSTERA, A. 1988. Informe sobre investigaciones arqueológicas en Calar. Boletín de la Sociedad Chilena de Arqueología 8: 1.

1996. San Pedro de Atacama: Nodo de complementariedad reticular. En La integración surandina cinco siglos después, X. Albó, M. I. Arratia, J. Hidalgo, L. Núñez, A. Llagostera, M. I. Remy y B. Reresz (Eds.), Universidad Católica del Norte y Centro de Estudios Regionales Andinos Bartolomé de las Casas, pp. 1742. Estudios y Debates Regionales Andinos 91, Cusco.

LlAGOSTERA, A. y M. A. COSTA, 1999. Patrones de asentamiento en la época agroalfarera de San Pedro de Atacama (norte de Chile). Estudios Atacameños 17: 175-206.

LLAGOSTERA, A., A. M. BARÓN y L. BRAVO, 1984. Investigaciones arqueológicas en Tulor 1. Estudios Atacameños 7: 133-149.

MENA, F. 1981. Patrones de movilidad durante el Complejo Chiu Chiu en el Arcaico Tardío, II región. Tesis de licenciatura en Arqueología. Universidad de Chile, Santiago.

MONTT, I. 2006a. Evidencias rupestres de Ghatchi (cuenca del río Vilama, San Pedro de Atacama). Tesis de magíster en Antropología. Universidad Católica del Norte, San Pedro de Atacama.

2006b. Las representaciones rupestres de Ghatchi o2Vigo en el contexto rupestre local y regional (cuenca del río Vilama, San Pedro de Atacama). Actas del XVII Congreso Nacional de Arqueología Chilena, vol. 1, pp. 133-143. Valdivia.

NIELSEN, A. 2006. Estudios internodales e interacción interregional en los Andes circumpuneños: Teoría, método y ejemplos de aplicación. En Esferas de interacción prehistóricas y fronteras nacionales modernas en los Andes Sur Centrales, H. Lechtman (Ed.), pp. 29-69. Instituto de Estudios Peruanos, Lima. 
NÚÑEZ, L. 1981. Asentamiento de cazadores recolectores tardíos de la Puna de Atacama: Hacia el sedentarismo. Chungara 8: 137-168.

1992. Fase Tilocalar: Nuevas evidencias formativas en la Puna de Atacama (norte de Chile). En Formativo sudamericano, una revaluación, P. Ledergerber-Crespo (Ed.), pp. 227-242. Ediciones ABYA-YALA, Quito.

1994. Emergencia de complejidad y arquitectura jerarquizada en la Puna de Atacama: Las evidencias del sitio Tulan 54. En Taller "De Costa a Selva: Producción e intercambio entre los pueblos agroalfareros de los Andes Centro Sur", M. E. Albeck (Ed.), pp. 85-115. Instituto Interdisciplinario de Tilcara, San Salvador de Jujuy.

1995. Evolución de la ocupación y organización del espacio atacameño. En Agua, ocupación del espacio y economía campesina en la región atacameña. Aspectos dinámicos, L. Pourrut y L. Núñez (Eds.), pp. 18-6o. Universidad Católica del Norte, Antofagasta.

2005. La naturaleza de la expansión aldeana durante el Formativo Tardío en la cuenca de Atacama. Chungara 37 (2): 165-193.

NÚÑEZ, L. y T. DILLEHAY, 1979 [1995]. Movilidad giratoria, armonía social y desarrollo en los Andes Meridionales: Patrones de tráfico e interacción económica (Ensayo). Universidad Católica del Norte, Antofagasta.

NúÑEZ, L. y C. SANTORO, 1988. Cazadores de la Puna Seca y Salada del Área Centro Sur andina (norte de Chile). Estudios Atacameños 8: 11-6o.

NÚÑEZ, L., M. GROSJEAN e I. CARTAJENA, 1999. Un ecorrefugio oportunístico en la Puna de Atacama durante eventos áridos del Holoceno Medio. Estudios Atacameños 17: 125-174.

NÚÑEZ, L., I. CARTAJENA, C. CARRASCO, P. DE SOUZA y M. GROSJEAN, 2006. Emergencia de comunidades pastoralistas formativas en el sureste de la Puna de Atacama. Estudios Atacameños 32: 93-117.

OLIVERA, D. 1997. El recurso Camelidae en sociedades agropastoriles tempranas del Noroeste Argentino, entre 3000 y 1000 AP. Actas del XII Congreso Nacional de Arqueología Argentina, vol. 1, pp. 113-119. La Plata.

ORELLANA, M. 1988-1989. Los tipos alfareros tempranos de Calar y su contexto aldeano. Paleoetnológica 5: 73-86.

1990. Calar: Una aldea temprana del norte de Chile. Creces 3(11): $23-28$.
PIMENTEL, G. 2008. Evidencias formativas en una vía interregional entre San Pedro de Atacama y el Altiplano de Lípez. Estudios Atacameños 35: 7-33.

POLLARD, G. 1970. The cultural ecology of ceramic stage settlement in the Atacama Desert. Tesis de doctorado, Columbia University, Columbia.

SERRACINO, G. 1976. Tulor 4: 4 pozos de sondeo. Estudios Atacameños 4: 24-31.

SINCLAIRE, C., M. URIBE, P. AYALA y J. GONZÁLEZ, 1998. La alfarería del período Formativo en la región del Loa Superior: Sistematización y tipología. Contribución Arqueológica 5: 285-314.

STOVEL, E. 1997. Habitational análisis and cultural contact at coyo Aldea, Northern Chile. The surface deposits. Tesis de magíster en Antropología, Graduate School of the State University of New York, Binghamton.

TARRAGÓ, M. 1989. Contribución al conocimiento arqueológico de las poblaciones de los oasis de San Pedro de Atacama en relación con los otros pueblos puneños, en especial el sector septentrional del valle Calchaquí. Tesis de doctorado en Historia, Especialidad Antropología. Universidad Nacional de Rosario, Facultad de Humanidades y Artes, Rosario.

URIBE, M. 2002. Sobre alfarería, cementerios, fases, procesos y la construcción de Atacama en la prehistoria tardía (800-1600 DC). Estudios Atacameños 22: 7-31.

2006. Sobre cerámica, su origen y complejidad social en los Andes del desierto de Atacama, norte de Chile. En Esferas de interacción prehispánicas y fronteras nacionales modernas. Los Andes Sur Centrales, H. Lechtman (Ed.), pp. 449-502. Institute of Andean Research e Instituto de Estudios Peruanos, Lima.

URIBE, M., L. ADÁN, 2003 Ms Historia cultural y evolución social en los períodos tardíos de San Pedro de Atacama y su relación con la cuenca del río Loa. Manuscrito en poder de los autores.

VIDAL, A. 2006a. Patrones de uso de los recursos vegetales durante el período Formativo en los oasis de San Pedro de Atacama. Memoria de Titulo. Departamento de Antropología, Facultad de Ciencias Sociales, Universidad de Chile, Santiago.

2006b. Patrones de uso de los recursos vegetales durante el período Formativo (1000 AC-500 DC) en los oasis de San Pedro de Atacama. Actas del XVII Congreso Nacional de Arqueología Chilena, vol. 2, pp. 1291-1302. Valdivia. 